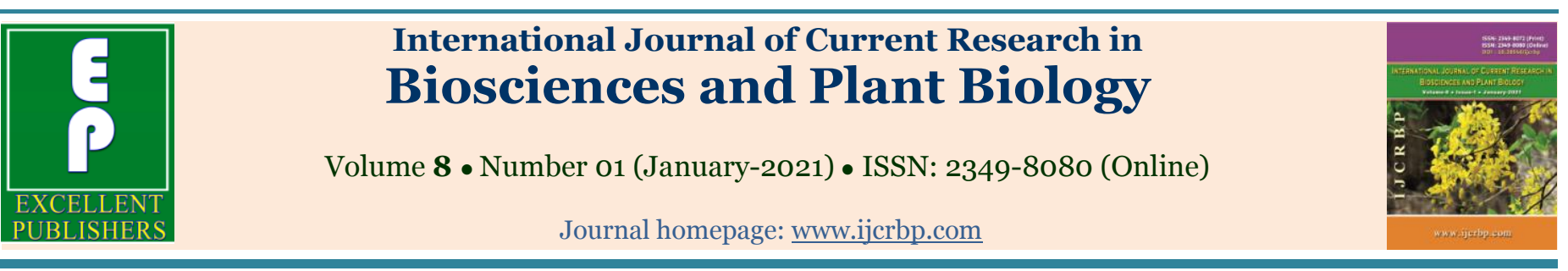

Review Article

doi: https://doi.org/10.20546/ijcrbp.2021.801.002

\title{
Recent updates on the role of herbal medicine for Alzheimer's disease (Dementia)
}

\author{
Ravindra B. Malabadi ${ }^{1}{ }^{*}$, Kiran P. Kolkar ${ }^{2}$, Neelambika T. Meti ${ }^{3}$ Raju K. Chalannavar $^{1}$ \\ ${ }^{I}$ Department of Applied Botany, Mangalore University, Mangalagangotri-574199, Mangalore, Karnataka State, India \\ ${ }^{2}$ Department of Botany, Karnatak Science College, Dharwad, Karnataka state, India \\ ${ }^{3}$ Plant Biotechnology Laboratory, Rajiv Gandhi Institute of IT and Biotechnology, Bharati Vidyapeeth University, Pune-Satara \\ Road, Katraj, Pune - 411046, Maharashtra State, India
}

*Corresponding author; e-mail: rbmalabadi_b3g@yahoo.com

\begin{tabular}{ll}
\hline Article Info & Abstract \\
\hline Keywords: & This review paper highlights the use of medicinal plants in the management of Alzheimer's disease and \\
Alzheimer's disease & memory deficit. Alzheimer's disease is the most common form of dementia, a serious brain disorder \\
Acetylcholine & that impacts daily living through memory loss and cognitive changes. Alzheimer's disease is also age- \\
Brain disorder & related neurodegenerative disorders caused by progressive loss of structure or function of neurons, \\
Dementia & resulting in neuronal cell death. Alzheimer's patients have an acetylcholine deficiency. Stressful \\
Herbal medicine & conditions, free radicle scavanging and oxidation are often associated with loss of memory and \\
Neuroprotective & $\begin{array}{l}\text { cognitive functions, which may lead to threats of schizophrenia and Alzheimer's disease. However, the } \\
\text { use of allopathic drugs has resulted in the adverse side effects on the human body and thus limits the } \\
\text { use of such drugs. Herbal cognitive enhancer drugs have shown their potent effect in Alzheimer's } \\
\text { disease due to their antioxidant and neuropharmacological actions. The use of natural cognitive } \\
\text { enhancers evidenced to improve mental functions such as cognition, memory, intelligence, motivation, } \\
\text { attention and concentration. Traditional Ayurvedic herbal system of medicine is fundamentally } \\
\text { preventive, protective, nutritive, curative and less expensive. Therefore, the use of herbal medicine for } \\
\text { the treatment of Alzheimer's disease is a novel approach without any side effects. }\end{array}$
\end{tabular}

- Received: 02 December 2020 • Revised: 29 December 2020 • Accepted: O3 January 2021 • Published Online: 6 January 2021

\section{Introduction}

Alzheimer's disease is characterized by the profound memory loss affecting daily routine life. Memory impairment (short memory loss) is the hallmark symptom of Alzheimer's disease (Katzman, 1976; Wernicke and Reischies, 1994). Alzheimer's is the most common form of dementia. Alzheimer's disease is a neurodegenerative pathology, is the most common form of mixed dementia (Chang et al., 2016). Mixed dementia is a condition in which Alzheimer's disease and vascular dementia occur together. Alzheimer's disease is a brain disorder named after German physician Aloes Alzheimer, who first described it in 1906 (Katzman, 1976; Wernicke and Reischies, 1994). Dementia is a leading cause of mental and physical disability (Chang et al., 2016). The cause and progression of Alzheimer's disease are not well 
understood. Research indicates that the Alzheimer's disease is associated with plaques and tangles in the brain (Rajagopal et al., 2013). Dementia is a syndrome associated with progressive impairments in memory and learning ability, memory loss, confusion, cognitive skills, disorientation, recent memory loss, and mood changes, forgetfulness, behaviour, insomnia, anxiety, depression, disruptive behaviour, and hallucinations, activities of daily living, and quality of life (Chang et al., 2016; Sharma et al., 2020; Sharma et al., 2014). The loss of memory is considered to be the result of a shortage of the nerve transmitter acetylcholine (Chang et al., 2016). Several studies have found evidence that Alzheimer's disease is a disease that is caused by the decreased metabolic activity in the brain (Chang et al., 2016; Sharma et al., 2020; Sharma et al., 2014). It is possible to increase the level of this transmitter in the brain by inhibiting the activity of the enzyme acetylcholinesterase, which splits or breaks down the transmitter substance (Katzman, 1976; Wernicke and Reischies, 1994; Chang et al., 2016; Sharma et al., 2020; Sharma et al., 2014). Several studies have revealed that natural antioxidants, such as vitamin E, vitamin $\mathrm{C}$, and beta-carotene, may help in scavenging free radicals generated during the initiation and progression of this disease. Drugs that inhibit the breakdown of the messenger or transmitter acetylcholine delay the development of the disease (Katzman, 1976; Wernicke and Reischies, 1994; Chang et al., 2016).

\section{Alzheimer's disease}

Memory is the ability of an individual to record sensory stimuli, events, information, etc., retain them over a short or long period of time, and recall the same at a later date when needed (Chakravarthi et al., 2013; Pastorino et al., 2018; Dhingra et al., 2004; Sharma and Agrawal, 2013; Obolentseva et al., 1999). Learning is the process of acquiring knowledge about the world and memory could be considered as the retention of the acquired knowledge, which can be recalled as and when needed (Chakravarthi et al., 2013; Pastorino et al., 2018; Dhingra et al., 2004; Sharma and Agrawal, 2013; Obolentseva et al., 1999). Dementia is a mental disorder characterized by loss of intellectual ability, which invariably involves impairment of memory and also other higher mental functions (Chakravarthi et al., 2013; Pastorino et al., 2018; Dhingra et al., 2004; Sharma and Agrawal, 2013; Obolentseva et al., 1999). The most common cause of dementia is
Alzheimer's disease, which is a progressive neurodegenerative disorder associated with loss of neurons in distinct brain areas (Chakravarthi et al., 2013; Pastorino et al., 2018; Dhingra et al., 2004; Sharma and Agrawal, 2013; Obolentseva et al., 1999). Furthermore, etiology of neurodegenerative disorders is linked to genetic defect that is $10-15 \%$ of total cases. In Alzheimer's disease, loss of neurons appears in subcortical structure, cortex and hippocampus. Various compounds have been identified by phytochemical studies such as alkaloids, sterols, triterpenes, polyphenols, tannins, flavonoids and lignins that have pharmacological activities including anticholinesterase and anti-amyloidogenic (Sharma et al., 2020; Sharma et al., 2014; Singh et al., 2011; Shukla et al., 2006; Esfandiari et al., 2018; Heneka and O'Banion, 2007; Hardy and Selkoe, 2002; Nunomura et al., 2006; Balakumbahan et al., 2010).

There are numerous types of dementia, among which vascular dementia is the second most common cause after Alzheimer's disease. Vascular dementia often coexists with other forms of dementia especially Alzheimer's disease (Liu and Chang, 2006). Other common forms of dementia include Parkinson's disease, dementia with Lewy bodies, frontotemporal dementia, Huntington's disease, and alcohol related dementia (Chang et al., 2016). Alzheimer's disease is also associated with functional decline, and behavioural disturbances leading to the cause of disability (Liu and Chang, 2006; Khondzadeh and Abhasi, 2006). The incidence and prevalence of Alzheimer's disease rose with increasing age, especially for those over the age of 65 years (Katzman, 1976; Khondzadeh and Abhasi, 2006; Evans et al., 1989). Therefore, there is a significant clinical challenge to treat patients suffering from Alzheimer's disease.

\section{Alzheimer's disease: diagnosis and treatment}

The first drug approved for general clinical use in Alzheimer's disease was tacrine (Khondzadeh and Abhasi, 2006). However, the use of tacrine is limited due to adverse effects such as hepatotoxicity (Watkins et al., 1994). Anti-oxidants are effective for Alzheimer's disease because they aid in reducing the free radicals that damage the brain cells (Howes and Houghton, 2012). The demonstration of damage to the cholinergic pathways in the brain leads to great interest in drug development. Acetylcholinesterase inhibitors are usually prescribed to treat Alzheimer's disease. These 
drugs help in enhancing cognitive functions such as memory and thoughts (Sharma et al., 2020; Sharma et al., 2014; Singh et al., 2011; Shukla et al., 2006; Esfandiari et al.. 2018; Heneka and O'Banion, 2007; Hardy and Selkoe, 2002; Nunomura et al., 2006; Balakumbahan et al., 2010).

The tau and amyloid hypothesis has led to focus on tau and amyloid as treatment targets. The current therapeutic goals are to decrease amyloid levels and prevent amyloid toxicity/aggregation and tau aggregation/phosphorylation in Alzheimer's disease patients (Sharma et al., 2020; Sharma et al., 2014; Singh et al., 2011; Shukla et al., 2006; Esfandiari et al., 2018; Heneka and O'Banion, 2007; Hardy and Selkoe, 2002; Nunomura et al., 2006; Balakumbahan et al., 2010). Other strategies, such as hormone therapy, antioxidants, cholesterol lowering agents, antiinflammatory agents and vaccinations are also being investigated for treating Alzheimer's disease (Lahiri et al., 2002). Probiotics have been reported for their efficacy to enhance memory (Lyte, 2011). Probiotics are used as antidepressant in Alzheimer's disease (Misra and Medhi, 2013). It reduces anxiety like behavior and attenuates psychological stress. Neurochemicals are produced by microbes. Immunological and neurological effects are induced by probiotics. Probiotics also have immunomodulating activity (Misra and Medhi, 2013). Cholinesterase inhibitors have a modest clinical effect on the Alzheimer's disease symptoms. Glutamate receptor antagonists are the most effective pharmaceutical options for the treatment of Alzheimer's disease. The mechanism of new generation of acetyl and butyryl cholinesterase inhibitors is being studied and investigated in clinical trials for Alzheimer's disease (Sharma et al., 2020; Sharma et al., 2014; Singh et al., 2011; Shukla et al., 2006; Esfandiari et al., 2018; Heneka and O'Banion, 2007; Hardy and Selkoe, 2002; Nunomura et al., 2006; Balakumbahan et al., 2010). However, memantine currently available $N$-methyl-daspartate receptor antagonist - does not prevent the deterioration of dementia (Tian et al., 2010). Alzheimer's, including long-term exposure to silicon or aluminium, chronic exposure to other toxins, freeradical damage, and traumatic head injury. Other diseases such as diabetes, high blood pressure, and high cholestero may also be risk factors for Alzheimer's and stroke-related dementia (Tian et al., 2010; Balakumbahan et al., 2010).

Among the different types of drugs that can modify cholinergic neurotransmission, the only class of drugs known so far to be effective for the symptomatic treatment of Alzheimer's disease are the acetylcholinesterase inhibitors (Rainer, 1997; Heinrich and Teoh, 2004; Salehi Sourmaghi et al., 2010; Rockwood et al., 2001; Fulton and Benfield, 1996; Kewitz, 1997; Harvey, 1995; Bickel, 1991; Dal-Bianco et al., 1991; Bubeva-Ivanova, 1957; Erkinjunti et al., 2002; Farlow, 2001; Parys, 1998). These drugs act by slowing the biochemical breakdown of acetylcholine and thereby, at least theoretically, prolonging cholinergic neurotransmission. Humans have two types of cholinesterase: acetyl and butyryl. The physiological role of butyrylcholinesterase is unknown, but levels of this enzyme have been shown to increase as Alzheimer's disease progresses, whereas levels of acetylcholinesterase decrease (Rainer, 1997; Heinrich and Teoh, 2004; Salehi Sourmaghi et al., 2010; Rockwood et al., 2001; Fulton and Benfield, 1996; Kewitz, 1997; Harvey, 1995; Bickel, 1991; Dal-Bianco et al., 1991; Bubeva-Ivanova, 1957; Erkinjunti et al., 2002; Farlow, 2001; Parys, 1998). Both enzymes are found in neuritic plaques, and their inhibition with cholinesterase inhibitors may modify the deposition of beta-amyloid, a key component of the pathophysiology of Alzheimer's disease. The clinical significance of this action, in terms of slowing progression of the disease has yet to be established (Rainer, 1997; Heinrich and Teoh, 2004; Salehi Sourmaghi et al., 2010; Rockwood et al., 2001; Fulton and Benfield, 1996; Kewitz, 1997; Harvey, 1995; Bickel, 1991; Dal-Bianco et al., 1991; Bubeva-Ivanova, 1957; Erkinjunti et al., 2002; Farlow, 2001; Parys, 1998).

The hallmark diagnosis of Alzheimer's disease features includes formation of senile plaques and neurofibrillary tangles (Sanka et al., 2018). Numerous hypotheses have been put forward on the basis of the various causative factors in order to explain this multifactorial disorder (Sanka et al., 2018). Some of them included are: cholinergic hypothesis, amyloid beta hypothesis, Tau hypothesis and Inflammation hypothesis (Sanka et al., 2018). Various therapeutic targets to treat Alzheimer's disease are 1) Targeting amyloid beta protein (Antiamyloid approach), 2) Targeting amyloid transport, 3) Modulation of Secretase enzyme, 4) Targeting amyloid clearance, 5) Amyloid based vaccination therapy, 6) Targeting Tau protein, and 7) Neurogenesis (Sanka et al., 2018). There are many categories of AntiAlzheimer's drugs available for management of Alzheimer's disease in the market but due to lack of 
patient compliance successful outcomes were not observed (Sanka et al., 2018). Apart from this including nutraceuticals in diet daily routine, aromatherapy, modifications in the regular schedule, practicing yoga regularly relaxes mind and body from tensions, insomnia, blood circulation, detoxification of organs due to rhythmic breathings and reduce frequency of incidence of headache are proven to show best results by relieving stress according to survey (Sanka et al., 2018).

Recently Cummings et al. (2020) reported that there are 121 unique therapies in clinical trials for Alzheimer's disease have been registered on clinicaltrials.gov (Cummings et al., 2020). The largest numbers of drugs in the Alzheimer's disease pipeline are putative diseasemodifying agents targeting disease onset or progression (Cummings et al., 2020). There is a growing number of repurposed agents (approved from non- Alzheimer's disease indication) in the pipeline; repurposed agents now comprise $43 \%$ of the pipeline (Cummings et al., 2020). The 2020 pipeline has innovations in clinical trials and tretment targets that provide hope for greater success in Alzheimer's disease drug development programs (Cummings et al., 2020). Review of clinical trials over the past 5 years demonstrated that there is progressive emphasis on non- amyloid targets, including candidate treatments for inflammation, synapse and neuronal protection, vascular factors, neurogenesis, and epigenetic interventions (Cummings et al., 2020). There has been a marked growth in repurposed agents in the pipeline (Cummings et al., 2020).

In a recent major breakthrough, study demonstrated that Bojungikgitang (in Korean, Bozhongyiqitang in Chinese, Hochuekkito in Japanese) may inhibit amyloid-b aggregation and increase antioxidant activity and therefore successfully be used in the treatment of Alzheimer's disease (Lee et al., 2020; Lim et al., 2018; Kaushik et al., 2018). Several other clinical studies show that Ukgansan (in Korean, Yigansan in Chinese, Yokukansan in Japanese) improved behavioral and psychological symptoms associated with multiple types of dementia (Lee et al., 2020; Lim et al., 2018; Kaushik et al., 2018). A retrospective study showed that compared to conventional therapy alone, adding Chinese herbal medicine had significant benefits in Alzheimer's disease: patients, which were more pronounced with time (Lee et al., 2020; Lim et al., 2018; Kaushik et al., 2018). In this study, cognitive decline was substantially decelerated in cases of moderate severity, while the cognitive function was largely stabilized in cases of mild severity over 2 years. (Lee et al., 2020; Lim et al., 2018; Kaushik et al., 2018).

\section{Alzheimer's disease: Herbal medicine treatment}

Traditional herbal medicine has the potential to treat the symptoms of Alzheimer's disease, and this might be due to the multitarget intervention effects of herbal medicine (Lee et al., 2020; Lim et al., 2018; Kaushik et al., 2018; Yang et al., 2017; May et al., 2016). The possible mechanisms for this are anti-inflammatory, antiapoptotic, and antioxidant actions (Lee et al., 2020; Lim et al., 2018; Kaushik et al., 2018; Yang et al., 2017; May et al., 2016). which include protecting neurons from amyloid-b damage, inhibiting amyloid-b secretion, and suppressing amyloid-b-induced oxidative stress and apoptosis (Lee et al., 2020; Lim et al., 2018; Kaushik et al., 2018; Yang et al., 2017; May et al., 2016). In this regard, herbal medicine may have the potential to overcome the limitations of conventional medicine (Lee et al., 2020; Lim et al., 2018; Kaushik et al., 2018; Yang et al., 2017; May et al., 2016).

Herbs have anti-inflammatory and antioxidant activities that may be used in the treatment of Alzheimer's disease (Chang et al., 2016). Anti-inflammatory herbs may reduce inflammation of the brain tissue in Alzheimer's. Acetylcholine is a neurotransmitter that plays a key role in cognitive function and reasoning (Chang et al., 2016). The brains of Alzheimer's disease, a progressive type of dementia, have abnormally low acetylcholine concentrations (Chang et al., 2016). This means that any compound that enhances the cholinergic system in the brain may be useful in treating Alzheimer's disease and similar brain malfunctions (Chang et al., 2016). The herbs that inhibit acetylcholinesterase contain natural COX-2 inhibitors, also reported as medicinal herbs, for Alzheimer's disease indication (Chang et al., 2016).

India is the largest producer of plant-based drugs in traditional medicines for the treatment of various diseases (Malabadi et al., 2007; Chakravarthi et al., 2013; Pastorino et al., 2018; Dhingra et al., 2004; Sharma and Agrawal, 2013; Obolentseva et al., 1999). The important traditional therapeutic methods are Ayurvedic, Homeopathy, Unani and Sidha systems of medicine. Unani system of medicine offers traditionally a highly scientific health care therapy as a divine gift and as a result the global interest of the 
medical profession is focused on medicinal plants (Malabadi et al., 2007). Therefore, traditional medicines are safe and harmless which treat the patients with fewer or no side effects. A number of herbs employed in the traditional system of medicine have yielded positive results in the treatment of human health disorders (Chakravarthi et al., 2013; Pastorino et al., 2018; Dhingra et al., 2004; Sharma and Agrawal, 2013; Obolentseva et al., 1999). Phytotherapy is a major contributor to the discovery of new, safer and effective plant based medicines (Malabadi et al., 2007; Malabadi, 2008; Malabadi and Vijayakumar, 2008; Malabadi et al., 2009, 2010a, 2010b; Malabadi et al., 2011, 2012a, 2012b, 2012c, 2012d; Malabadi et al., 2016a, 2016b, 2016c, 2016d, 2016e; Malabadi et al., 2017a, 2017b). Medicinal plants have been used by indigenous populations, plays an important role in the treatment of human health disorders (Singh et al., 2011; Das et al., 1998; Ranpariya et al., 2011).

Modern drugs have been developed from isolated compounds of medicinal plants, based on their ethnopharmacological uses/applications (Malabadi et al., 2007; Malabadi, 2008; Malabadi and Vijayakumar, 2008; Malabadi et al., 2009, 2010a, 2010b; Malabadi et al., 2011, 2012a, 2012b, 2012c, 2012d; Malabadi et al., 2016a, 2016b, 2016c, 2016d, 2016e; Malabadi et al., $2017 \mathrm{a}, 2017 \mathrm{~b})$. The role of natural products on drug development has been increasing, since bioactive compounds are directly used as therapeutic agents of biologically active compounds (Singh et al., 2011; Das et al., 1998; Ranpariya et al., 2011). Therefore, plants provide a desirable therapeutic effect with reduced side effects often associated with conventional medication (Malabadi, 2008; Malabadi and Vijayakumar, 2008; Malabadi et al., 2009, 2010a, 2010b; Malabadi et al. 2011, 2012a, 2012b, 2012c, 2012d; Malabadi et al. 2016a, 2016b, 2016c, 2016d, 2016e; Malabadi et al., $2017 \mathrm{a}, 2017 \mathrm{~b})$. The combined treatment of herbal medicines and synthetic drugs reduced some adverse effects of highly potent drugs. Plants can be used as therapeutic resources in the form of herbal infusion, pharmaceutical preparations such as extracts, tablets or capsules by extracting and purifying active compounds (Singh et al., 2011; Das et al., 1998; Ranpariya et al., 2011). However, a major limitation on the use of plants in the phyto- pharmaceutical area is the lack consistency in the levels of compounds present in the extract due to natural variability, leading to inconsistent results upon scientific validation (Singh et al., 2011; Das et al., 1998; Ranpariya et al., 2011).
This review paper has been developed on the basis of literature survey, animal, and in vitro studies, presented the following herbal medicines in the treatment of Alzheimer's disease.

\section{Medicinal plants used in the treatment of Alzheimer's disease}

\section{1) Gingko biloba (maidenhair tree)}

Ginkgo biloba belongs to Ginkgoaceae is a family of Gymnosperms. Ginkgos (maidenhair tree) is a longlived, deciduous, shade tree normally reaching a height of $20-35 \mathrm{~m}(66-115 \mathrm{ft})$, with some specimens native to China being over $50 \mathrm{~m}$ (160 ft) (Chang et al., 2016). Ginkgos are dioecious, with separate sexes, some trees being female and others being male. Male plants produce small pollen cones with sporophylls, each bearing two microsporangia spirally arranged around a central axis (Chang et al., 2016; Tian et al., 2010). The leaves are unique among seed plants, being fan-shaped with veins radiating out into the leaf blade (Chang et al., 2016). The leaves were harvested for the medicinal purposes particularly for the treatment of Alzheimer's disease (Chang et al., 2016). Ginkgo leaf extract is widely used for ageing-related memory disorders in many European and Asian countries (Chang et al., 2016; Tian et al., 2010). The principal constituents of ginkgo include flavonol glycosides (e.g., quercetin and kaempferol) and terpenoids (e.g., ginkgolide and bilobalide) (Chang et al., 2016). Ginkgo treatment in healthy young adults has been shown to improve speed of processing, working memory, executive function, and cognition (Chang et al., 2016). Numerous clinical trials demonstrated that ginkgo improves memory loss and concentration and decreases anxiety in patients with dementia and/or $\mathrm{VaD}$ (Chang et al., 2016; Tian et al., 2010). The evidence to support the use of gingko for dementia remains controversial (Chang et al., 2016). The Jammu Kashmir Medicinal Plants Introduction Centre, India has launched Ginkgo Project for propagation of Ginkgo saplings and saplings were available for plantation. Ginkgo biloba is also available in North America, Afghanistan, Nepal, Iran and Bhutan.

\section{2) Zingiber officinale}

Zingiber officinale belongs to the family Zingiberaccae. It improves memory impairment induced by scopolamine via inhibition of acetylcholinesterase activity (Hanumanthacar et al., 2006; Masuda et al., 
1997; Malhotra and Singh, 2003; Gharibi et al., 2013; Rao et al., 2012; Gulkari and Maske, 2020; Rajagopal et al., 2013).

\section{3) Ficus racemosa}

Ficus racemosa belongs to the family Moraceae. Experimental data demonstrated the memory enhancing activity of Ficus racemosa bark in rats and found that Ficus racemosa (250 and $500 \mathrm{mg} / \mathrm{kg}$ ) significantly increased acetylcholine level in the hippocampus of rats (Akram and Nawaz, 2017; Faiyaz et al., 2011). This study demonstrated its potential to treat memory deficits in patients with Alzheimer's disease (Akram and Nawaz, 2017; Faiyaz et al., 2011). Oxidative stress is involved in the initial levels of Alzheimer's pathological cascade and several studies have found that oxidative stress compared to Alzheimer's pathological symptoms are premier and considered as an upstream cause (Faiyaz et al., 2011; Sharma et al., 2020; Sharma et al., 2014; Singh et al., 2011; Shukla et al., 2006; Esfandiari et al., 2018; Heneka and O'Banion, 2007; Hardy and Selkoe, 2002; Nunomura et al., 2006; Balakumbahan et al., 2010).

\section{4) Bacopa monnieri (Brahmi)}

Bacopa monnieri (Brahmi) belonging to family Scrophulariaceae, a well known nootropic herb (Chang et al. 2016; Dhanasekaran et al., 2007; Tian et al., 2010). The plant being traditional Ayurvedic medicine used for centuries as a memory enhancing, antiinflammatory, analgesic, antipyretic, sedative, and antiepileptic agent (Verma, 2014; Singh and Dhawan, 1997; Roodenrys et al., 2002; Tian et al., 2010; Aguiar and Borowski, 2013). Bacopa monnieri (Brahmi) is a creeping, glabrous, succulent herb rooting at nodes whose habitat includes wetlands and muddy shores with small oblong leaves and purple flowers, and native to Australia and India (Aguiar and Borowski, 2013). Bacopa monnieri (Brahmi) is also commonly found as a weed in rice fields, and grows throughout East Asia and the United States (Verma, 2014; Singh and Dhawan, 1997; Roodenrys et al., 2002; Tian et al., 2010; Aguiar and Borowski, 2013). The whole plant is used for therapeutic and medicinal purposes to treat various diseases and disorders (Verma, 2014; Singh and Dhawan, 1997; Roodenrys et al., 2002; Tian et al., 2010; Aguiar and Borowski, 2013). Bacopa monnieri (Brahmi) putatively involved with the low toxicity cognitive enhancing action of a medicinal Ayurvedic herb (Aguiar and Borowski, 2013; Chang et al., 2016). Bacopa monnieri (Brahmi) is traditionally used for various ailments, but is best known as a neural tonic and memory enhancer (Aguiar and Borowski, 2013). Numerous animal and in vitro studies have been conducted, with many evidencing potential medicinal properties (Aguiar and Borowski, 2013). The milieu of nootropic phytochemicals found within Bacopa monnieri (Brahmi) primarily triperpenoid saponins called bacosides, exhibit minimal observable adverse effects at standard dosages (Aguiar and Borowski, 2013). Bacopa monnieri (Brahmi) demonstrated increased anti-oxidant activity, free radical scavenging, binding and detoxification of metal ions, modifying levels of acetylcholine, hepatoprotective, and neuroprotective activity (Aguiar and Borowski, 2013). Experimental research also demonstrated several mechanisms of action-acetylcholinesterase inhibition, choline acetyltransferase activation, b-amyloid reduction, increased cerebral blood flow, and monoamine potentiation (Aguiar and Borowski, 2013). Bacopa monnieri (Brahmi) demonstrated immense potential in the amelioration of cognitive disorders, as well as prophylactic reduction of oxidative damage, and cognitive enhancement in healthy people (Verma, 2014; Singh and Dhawan, 1997; Roodenrys et al., 2002; Tian et al., 2010; Aguiar and Borowski, 2013). The constituents responsible for improving learning and memory are attributed to steroidal saponins and bacosides A and B (Tian et al., 2010; Aguiar and Borowski, 2013).

\section{5) Turmeric (Curcuma longa L.) (Haladi; Arashina in Kannada)}

Curcuma longa L. is a rhizomatous herbaceous perennial plant belonging to the ginger family Zingiberaceae, which is native to tropical South Asia. Turmeric (Curcuma longa L.) has been widely used as a common household remedy for cough, sore throat, memory enhancer, and respiratory ailments in Asia (Prasad and Aggarwal, 2011; Chang et al., 2016). Studies have proved that curcumin has antiinflammatory and antioxidant activities, and it helps in combating Alzheimer's disease (Prasad and Aggarwal, 2011; Chang et al., 2016). Curcumin and curcuminoids are the key bioactive components of turmeric consisting of three structurally closely related chemical components: curcumin, demethoxycurcumin, and bisdemethoxycurcumin (Chang et al., 2016). Experimental data from animal and/or in vitro studies 
demonstrated that curcumin can affect multiple pathological targets associated with dementia via inhibiting lipid peroxidation, scavenging reactive oxygen species, and reactive nitrogen species, inhibiting NF-kB activation, and its anti inflammatory actions (Chang et al., 2016). It has also been suggested that curcumin is able to directly bind small beta-amyloid species to block aggregation and fibril formation, and helps in the treatment of dementia (Chang et al. 2016). Curcumin offers protection effects against vascular dementia by exerting antioxidant and anti-inflammatory effects (Chang et al., 2016). Therefore, consumption of turmeric containing curry was associated with improved cognitive function (Chang et al., 2016; Tian et al., 2010).

\section{6) Centella asiatica (Gotu kola or Tiger Grass)}

Centella asiatica, a clonal, perennial herbaceous creeper belonging to the family Umbelliferae (Apiceae) is found throughout India growing in moist places up to an altitude of $1800 \mathrm{~m}$ (Brinkhaus et al., 2000; Gohil et al., 2010; Ganachari et al., 2004). It is also found in most tropical and subtropical countries growing in swampy areas, including parts of India, Pakistan, Sri Lanka, Madagascar, and South Africa and South pacific and Eastern Europe (Brinkhaus et al., 2000; Gohil et al., 2010; Ganachari et al., 2004). It is a tasteless, odourless plant that thrives in and around water (Gohil et al., 2010). It has small fan-shaped green leaves with white or light purple-to-pink or white flowers and it bears small oval fruit. The whole plant is used for medicinal purposes (Brinkhaus et al., 2000; Gohil et al., 2010; Ganachari et al., 2004). The primary active constituents of Centella asiatica are saponins (also called triterpenoids), which include asiaticosides, in which a trisaccharide moiety is linked to the aglycone asiatic acid, madecassoside and madasiatic acid (Gohil et al., 2010).

Extract from the leaves of Gotu Kola (Centella asiatica) has been used as an alternative medicine for memory improvement in the Indian Ayurvedic system of medicine for a long time (Brinkhaus et al., 2000; Gohil et al., 2010; Ganachari et al., 2004). Centella asiatica, commonly known as Indian pennywort or Asiatic pennywort, is a herbaceous, perennial plant in the flowering plant family Apiaceae (Brinkhaus et al., 2000; Gohil et al., 2010; Ganachari et al., 2004). It is used as a culinary vegetable and as a medicinal herb (Gohil et al., 2010), Centella asiatica is known to re- vitalize the brain and nervous system, increase attention span and concentration and combat aging (Gohil et al., 2010). In one study, derivatives of asiatic acid derivatives were shown to exert significant neuro protective effects on cultured cortical cells by their potentiation of the cellular oxidative defence mechanism (Brinkhaus et al., 2000; Gohil et al., 2010; Ganachari et al., 2004). Therefore, these agents were proved to be efficacious in protecting neurons from the oxidative damage caused by exposure to excess glutamate (Gohil et al., 2010). These derivatives may be candidates for a treatment of Alzheimers disease that protects neurons from beta-amyloid toxicity (Brinkhaus et al., 2000; Gohil et al., 2010; Ganachari et al., 2004).

\section{7) Crocus sativus (saffron or Kesara)}

Crocus sativus L. (Iridaceae), commonly known as saffron, is a perennial stemless medicinal herb that is widely cultivated in Iran and other countries such as India, China and Greece (Chang et al., 2016; Farokhnia et al., 2014; Akhondzadeh et al., 2010a; Akhondzadeh et al., 2010b; Srivastava et al., 2010; Sigiura et al., 1995; Abe and Saito, 2000). Commercial saffron comprises the dried red stigma with a small portion of the yellowish style attached (Srivastava et al., 2010). Saffron contains more than 150 volatile and aromayielding compounds mainly terpenes, terpene alcohol, and their esters (Chang et al., 2016; Farokhnia et al., 2014; Akhondzadeh et al., 2010a; Akhondzadeh et al., 2010b; Srivastava et al., 2010; Sigiura et al., 1995; Abe and Saito, 2000). The bitter taste and an iodoform or hay-like fragrance are caused by chemicals picrocrocin and safranal. Crocus sativus L. possesses a number of medicinally important activities such as antihypertensive, anticonvulsant, antitussive, antigentoxic and cytotoxic effects, anxiolytic aphrodisiac, antioxidant, antidepressant, antinociceptive, antiinflammatory, and relaxant activity (Chang et al., 2016; Farokhnia et al., 2014; Akhondzadeh et al., 2010a; Akhondzadeh et al., 2010b; Srivastava et al., 2010; Sigiura et al., 1995; Abe and Saito, 2000).

It also improves memory and learning skills, and increases blood flow in retina and choroid (Chang et al., 2016; Farokhnia et al., 2014; Akhondzadeh et al., 2010a; Akhondzadeh et al., 2010b; Srivastava et al., 2010; Sigiura et al., 1995; Abe and Saito, 2000). The saffron extract with two of its main ingredients, crocin and crocetin, improved memory and learning skills in ethanol-induced learning behavior impairments in mice 
and rats (Chang et al., 2016; Farokhnia et al., 2014; Akhondzadeh et al., 2010a; Akhondzadeh et al., 2010b; Srivastava et al., 2010; Sigiura et al., 1995; Abe and Saito, 2000). Oral administration of saffron may be useful in the treatment of neurodegenerative disorders and related memory impairment (Chang et al., 2016; Farokhnia et al., 2014; Akhondzadeh et al., 2010a; Akhondzadeh et al., 2010b; Srivastava et al., 2010; Sigiura et al., 1995; Abe and Saito, 2000). There is an increasing trend to prescribe the Crocus sativus in the treatment of Alzheimer's disease and memory deficits (Chang et al., 2016; Farokhnia et al., 2014; Akhondzadeh et al., 2010a; Akhondzadeh et al., 2010b; Srivastava et al., 2010; Sigiura et al., 1995; Abe and Saito, 2000). Crocin, the principal constituent of saffron and a strong antioxidant, has been suggested to be largely responsible for saffron's protective effect on the central nervous system (Chang et al., 2016; Farokhnia et al., 2014; Akhondzadeh et al., 2010a; Akhondzadeh et al., 2010b; Srivastava et al., 2010; Sigiura et al., 1995; Abe and Saito, 2000). It has also been suggested that saffron can act as an antidepressant and antiplatelet agent both of which may offer additional benefits for people with dementia/ Alzheimer's disease (Chang et al., 2016; Farokhnia et al., 2014; Akhondzadeh et al., 2010a; Akhondzadeh et al., 2010b; Srivastava et al., 2010; Sigiura et al., 1995; Abe and Saito, 2000). In more recent years, Crocus sativus (saffron) has been used for neurological conditions (Chang et al., 2016; Farokhnia et al., 2014; Akhondzadeh et al., 2010a; Akhondzadeh et al., 2010b; Srivastava et al., 2010; Sigiura et al., 1995; Abe and Saito, 2000). A 22-week double-blind RCT in Alzheimer's disease participants showed that saffron (30mg/day) resulted in comparable improvements in cognition to donepezil (10 mg/day) although better tolerated (Chang et al., 2016; Farokhnia et al., 2014; Akhondzadeh et al., 2010a; Akhondzadeh et al., 2010b; Srivastava et al., 2010; Sigiura et al., 1995; Abe and Saito, 2000). Another 16-week double-blind trial in Alzheimer's disease participants, comparing the same dose of saffron with placebo, showed saffron supplementation resulted in significantly better outcomes in cognitive function than placebo (Chang et al., 2016; Farokhnia et al., 2014; Akhondzadeh et al., 2010a; Akhondzadeh et al., 2010b; Srivastava et al., 2010; Sigiura et al., 1995; Abe and Saito, 2000).

\section{8) Punica granatum}

Pomegranate (Punica granatum) is the most important plant belonging to family Lythraceae (Punicaceae) known for neuroprotective properties (Haque et al., 2015; Jureneka, 2008). Pomegranate is used in various systems of medicine. Phytochemical screening of the Punica granatum exposed that it contains anthocynin, flavonoides, alkaloids, tannins, triterpenes and phytosterols (Haque et al., 2015; Jureneka, 2008). Punica granatum flower plays an important role in the treatment of neurological deficits in patients with diabetes mellitus (Akram and Nawaz, 2017; Cambay et al., 2011; Haque et al., 2015; Jureneka, 2008). Cambay et al., (2011) reported the efficacy of Punica granatum flower in learning and memory performance impaired by diabetes mellitus in rats and demonstrated that rats in the streptozocin group showed memory impairment than those in the control group (Akram and Nawaz, 2017; Cambay et al., 2011; Haque et al., 2015; Jureneka, 2008). Pomegranate juice as a remedy for inflammation, intestinal worms, persistent coughs, diarrhea, and dysentery (Haque et al., 2015; Jureneka, 2008). The pomegranate has been used in natural and holistic medicine to treat sore throats, coughs, urinary infections, digestive disorders, skin disorders, arthritis and to expel tapeworms. Administration of pomegranate flower powder led to improvement in learning abilities and memory retention in diabetic rats (Akram and Nawaz, 2017; Cambay et al., 2011; Haque et al., 2015; Jureneka, 2008). Pomegranate flower powder supplementation decreased oxidative stress and alleviated learning and memory impairment as compared to streptozocin induced diabetic rats (Akram and Nawaz, 2017; Cambay et al., 2011; Haque et al., 2015; Jureneka, 2008).

\section{9) Salvia officinalis L. (Sage)}

Salvia officinalis L. (Sage) is a perennial shrub in the family of Labiatae/Lamiaceae. Salvia is the largest genus of this family and includes near 900 species. Plants of this genus grow all over the world and the specie of Salvia officinalis is native to Middle East and Mediterranean areas (Ghorbani and Esmaeilizadeh, 2013; Kennedy et al., 2006; Russo et al., 2013; Eidi et al., 2006; Scholey et al., 2008; Moss et al., 2010; Moss et al., 2014; Akhondzadeh et al., 2003). The aerial parts of Salvia officinalis shrub hve a long history of use in cookery and traditional medicine. Because of its flavoring and seasoning properties, Salvia officinalis has been widely used in preparation of many foods.

In folk medicine of Asia and Latin America, it has been 
used for the treatment of different kinds of disorders including memory enhancer, seizure, ulcers, gout, rheumatism, inflammation, dizziness, tremor, paralysis, diarrhea, and hyperglycemia (Ghorbani and Esmaeilizadeh, 2013; Kennedy et al., 2006; Russo et al., 2013; Eidi et al., 2006; Scholey et al., 2008; Moss et al., 2010; Moss et al., 2014; Akhondzadeh et al., 2003). In traditional medicine of Europe, Salvia officinalis has been used to treat mild dyspepsia (such as heartburn and bloating), excessive sweating, age-related cognitive disorders, and inflammations in the throat and skin (Ghorbani and Esmaeilizadeh, 2013). Clinical trials confirmed the results of animal studies and demonstrated that Salvia officinalis enhances cognitive performance both in healthy participants and patients with cognitive impairment or dementia (Ghorbani and Esmaeilizadeh, 2013; Kennedy et al., 2006; Russo et al., 2013; Eidi et al., 2006; Scholey et al., 2008; Moss et al., 2010; Moss et al., 2014; Akhondzadeh et al., 2003). Moss et al. (2010) reported that the aroma of Salvia officinalis essential oil could enhance prospective memory performance in healthy adults. Also, Scholey et al. (2008) showed that ethanolic extract of Salvia officinalis improved memory and attention in healthy older subjects. A randomized controlled trial by Akhondzadeh etal. (2003) showed that a 4-month treatment with hydroalcoholic extract of Salvia officinalis improved cognitive functions in patients with mild to moderate Alzheimer's disease (Akhondzadeh et al., 2003).

The mechanisms responsible for cognitive- and memory-enhancing effects of Salvia officinalis, a potential interaction with cholinergic system has been suggested (Ghorbani and Esmaeilizadeh, 2013; Kennedy et al., 2006; Russo et al., 2013; Eidi et al., 2006; Scholey et al., 2008; Moss et al., 2010; Moss et al., 2014; Akhondzadeh et al., 2003). Eidi and coworkers found that activation of muscarinic and nicotinic receptors by pilocarpine and nicotine, respectively, potentiated memory-enhancing effects of Salvia officinalis (Ghorbani and Esmaeilizadeh, 2013; Kennedy et al., 2006; Russo et al., 2013; Eidi et al., 2006; Scholey et al., 2008; Moss et al., 2010; Moss et al., 2014; Akhondzadeh et al., 2003). On the other hand, blockade of muscarinic and nicotinic receptors by scopolamine and mecamylamine, respectively, attenuated this effect (Ghorbani and Esmaeilizadeh, 2013). In addition, Salvia officinalis has been reported to inhibit acetylcholinesterase activity (Ghorbani and Esmaeilizadeh, 2013; Kennedy et al.,
2006; Russo et al., 2013; Eidi et al., 2006; Scholey et al., 2008; Moss et al., 2010; Moss et al., 2014; Akhondzadeh et al., 2003). To date, inhibitors of acetylcholinesterase are the leading therapeutics of Alzheimer's disease and Salvia officinalis might be a promising source for developing therapeutic agents for this disease (Ghorbani and Esmaeilizadeh, 2013; Kennedy et al., 2006; Russo et al., 2013; Eidi et al., 2006; Scholey et al., 2008; Moss et al., 2010; Moss et al., 2014; Akhondzadeh et al., 2003).

\section{0) Rosmarinus officinalis $\mathbf{L}$. (Satapatrika) \\ (Rosemary)}

Rosmarinus officinalis L. popularly known as rosemary, is a plant belonging to the family Lamiaceae native to the Mediterranean region and cultivated around the world (De- Oliveira et al., 2019). Besides the therapeutic purpose, it is commonly used as a condiment and food preservative (Al-Sereiti et al., 1999; Kayashima and Matsubara, 2012; De-Oliveira et al., 2019; Borges et al., 2019). It is a perennial and aromatic plant, shrub-shaped with branches full of leaves, having a height of up to two meters and green leaves that exude a characteristic fragrance (De-Oliveira et al., 2019). Rosmarinus officinalis L. (Rosemary) may be used as a spice in cooking, as a natural preservative in the food industry, and as an ornamental and medicinal plant (Al-Sereiti et al. 1999; Kayashima and Matsubara, 2012; De- Oliveira et al., 2019; Borges et al., 2019). Rosmarinus officinalis is constituted by bioactive molecules, responsible for implement several pharmacological activities, such as anti-inflammatory, antioxidant, antimicrobial, antiproliferative, antitumor and protective, inhibitory and attenuating activities (Al-Sereiti et al., 1999; Kayashima and Matsubara, 2012; De- Oliveira et al., 2019; Borges et al., 2019).

Rosmarinus officinalis can promote several pharmacological effects include (De-Oliveira et al., 2019; Al-Sereiti et al., 1999; Kayashima and Matsubara, 2012; Borges et al., 2019). The localized blood flow reduction in the brain is known as cerebral ischemia, caused by arteries obstruction or systematic hyperfusion, causing irreversible damage (Al-Sereiti et al., 1999; Kayashima and Matsubara, 2012; DeOliveira et al., 2019; Borges et al., 2019). Rosmarinus officinalis can promote reduction of lipid peroxidation, hydroxyl radical, and hydrogen peroxide action in some tissues, such as cerebral, renal, cardiac, and serum (Al-Sereiti et al., 1999; Kayashima and Matsubara, 
2012; De-Oliveira et al., 2019; Borges et al., 2019). This fact shows that the plant can control the release of oxidative stress promoting molecules which are harmful to brain health (Al-Sereiti et al., 1999; Kayashima and Matsubara, 2012; De- Oliveira et al., 2019; Borges et al. 2019). Rosmarinus officinalis (Satapatrika) contains the following natural COX-2 inhibitors: Apigenin, carvacrol, eugenol, oleanolic acid, thymol, and ursolic acid. 'If a synthetic COX-2 inhibitor could prevent Alzheimer's disease, so could a natural COX-2 inhibitor,' (Al-Sereiti et al., 1999; Kayashima and Matsubara, 2012; De- Oliveira et al., 2019; Borges et al. 2019). Some of the strongest antioxidant substances in Rosmarinus officinalis are carnosic acid and ferulic acid, which have even greater reported antioxidant activity than the widely common synthetic antioxidants butylated hydroxytoluene (BHT) and butylated hydroxyanisole (BHA) (Al-Sereiti et al., 1999; Kayashima and Matsubara, 2012; De-Oliveira et al., 2019; Borges et al., 2019). Therefore, Rosmarinus officinalis L. (Rosemary) has a promising future in the medical field, especially in the treatment and prevention of various cancers, infectious diseases and increasingly emerging diseases such as depression, Alzheimer's and Parkinson's diseases (Al-Sereiti et al., 1999; Kayashima and Matsubara, 2012; De-Oliveira et al., 2019; Borges et al., 2019).

\section{1) Matricaria recutita (German chamomile)}

Chamomile (Matricaria recutita $\mathrm{L}$.) or chamomilla is a well-known medicinal plant belongs to the family Asteraceae. Chamomile (Matricaria recutita L.) is one of the important medicinal herb native to southern and eastern Europe (Singh et al., 2011; Das et al., 1998; Ranpariya et al., 2011). It is also grown in Germany, Hungary, France, Russia, Yugoslavia, and Brazil. In India, the plant had been cultivated in Lucknow for about 200 years, and the plant was introduced in Punjab about 300 years ago during the Mughal period (Singh et al., 2011; Das et al., 1998; Ranpariya et al., 2011).

Chamomile is used mainly as an anti inflammatory and antiseptic, also antispasmodic and mildly sudorific (Singh et al., 2011; Das et al., 1998; Ranpariya et al., 2011). It is an ingredient of several traditional, unani, and homeopathy medicinal preparations. As a drug, it finds use in flatulence, colic, hysteria, and intermittent fever (Singh et al., 2011; Das et al., 1998; Ranpariya et al., 2011). The flowers of $M$. chamomilla contain the blue essential oil from 0.2 to $1.9 \%$ which finds a variety of uses (Singh et al., 2011; Das et al., 1998; Ranpariya et al., 2011).

Oxidative stress plays a key role in pathophysiology of many neurodegenerative disorders such as Alzheimer's disease, Parkinson's disease, Huntington's disease and dementia (Singh et al., 2011; Das et al., 1998; Ranpariya et al., 2011). Although Matricaria recutita L. (Asteraceae), German chamomile, is traditionally used for central nervous system (CNS)-related diseases, its anti stress properties have received little attention (Singh et al., 2011; Das et al., 1998; Ranpariya et al., 2011) German Chamomile is said to stimulate the brain, dispel weariness, calm the nerves, counteract insomnia, aid in digestion, break up mucus in the throat and lungs, and aid the immune system (Singh et al., 2011; Das et al., 1998; Ranpariya et al., 2011). Chamomile can relieve anxiety, and in higher doses, leads to drowsiness (Singh et al., 2011; Das et al., 1998; Ranpariya et al., 2011). One of the study demonstrated that potent neuro-protective activity of the methanol extract of German chamomile against $\mathrm{AlF}_{4}^{-}$-induced oxidative stress in rats (Singh et al., 2011; Das et al., 1998; Ranpariya et al., 2011).

\section{2) Cissampelos pareira}

Cissampelos pareira belongs to the family Menispermaceae. Nootropic effect of Cissampelos pareira was observed that may be due to decreased activity of acetylcholinesterase enzyme and increased antioxidant and anti-inflammatory activities (Pramodinee et al., 2011; Rao et al., 2012; Gulkari and Maske, 2020; Rajagopal et al.. 2013).

\section{3) Melissa officinalis L. (Lemon balm)}

Melissa officinalis, also known as lemon balm, common balm or sweet balm, is a perennial lemon-scented herb belonging to the Lamiaceae, is a medicinal plant that has been long used in various ethno-medical systems (Shakeri et al., 2016; Braidy et al., 2014). The current clinical evidences demonstrated that the daily oral dose of 600mg of Melissa officinalis extract is possibly safe and effective in the treatment of anxiety, mood and cognition problems (Shakeri et al., 2016; Braidy et al., 2014). Melissa officinalis has been traditionally used for the treatment of dementia and amnesia, two disorders that are closely associated with the Alzheimer's disease (Shakeri et al., 2016; Braidy et al., 2014). The plant has also been recorded as a treatment for psychosis. 
acetylcholinesterase inhibitors increase the level and duration of action of acetylcholine in brain synapses (Shakeri et al., 2016; Braidy et al., 2014). This cholinergic effect can alleviate Alzheimer's disease and its cognitive symptoms (mostly in the form of memory and learning deficits) as well as cognitive impairments in patients with schizophrenia (Shakeri et al., 2016; Braidy et al., 2014). Ethanol extract of Melissa officinalis can exert acetylcholinesterase inhibitory activity in a time- and dose dependent manner (Shakeri et al., 2016; Braidy et al., 2014). Acetylcholinesterase inhibitory activity of Melissa officinalis is mainly attributed to rosmarinic acid and some of its derivatives, and the plant essential oil (Shakeri et al., 2016; Braidy et al., 2014)

It has been shown that stimulation of acetylcholine receptors is another strategy for the treatment of Alzheimer's disease (Shakeri et al., 2016; Braidy et al., 2014). An $80 \%$ ethanol extract of Melissa officinalis could displace $[3 \mathrm{H}]-(\mathrm{N})$-nicotine and [3H]-(N)scopolamine (the ligand for muscarinic receptors) from human brain cell membranes bearing nicotinic or muscarinic acetylcholine receptors (Shakeri et al., 2016; Braidy et al., 2014). This finding suggests that compounds with a higher solubility in $80 \%$ ethanol than water, can be responsible for the observed displacing effect (Shakeri et al., 2016; Braidy et al., 2014). Historically, Melissa officinalis (lemon balm) was believed to sharpen memory (Shakeri et al., 2016; Braidy et al., 2014). Lemon balm can also temporarily improve cognitive decline as well as improve the mood for Alzheimer's patients (Shakeri et al., 2016; Braidy et al., 2014). Another study concluded the use of lemon balm for Alzheimer's disease (Shakeri et al., 2016; Braidy et al., 2014). Experimental study concluded that Melissa officinalis is one of several plants that may be useful in the prevention and treatment of Alzheimer's disease due to its ability to inhibit acetylcholinesterase and its antioxidant activity (Shakeri et al., 2016; Braidy et al., 2014). Another clinical trial investigated the effects of Melissa officinalis on cognition and mood of healthy humans showed that acute administration of the plant's ethanol extract $(600 \mathrm{mg})$ can modulate mood and cognitive performance (Shakeri et al., 2016; Braidy et al., 2014).

\section{4) Celastrus paniculatus}

Celastrus paniculatus belongs to the family Celastraceae. Celastrus paniculatus extracts protected of Glycyrrhiza glabra have widely been used worldwide in food, confectionery, and pharmaceutical products, and it is cultivated in the Mediterranean basin of Africa, in southern Europe, and in India (Chakravarthi et al., 2013; Pastorino et al., 2018; Dhingra et al., 2004; Sharma and Agrawal, 2013; Obolentseva et al., 1999). The chemical composition of Glycyrrhiza glabra is glycyrrhizin, glycyrrhetic acid, isoliquiritin, isoflavones, and their derivatives have been reported for several pharmacological activities like, expectorant, anti demulcent, antiulcer, anticancer, anti-inflammatory, memory enhancing agent, and antidiabetic (Chakravarthi et al., 2013; Pastorino et al., 2018; Dhingra et al., 2004; Sharma and Agrawal, 2013; Obolentseva et al., 1999).

Free radicals and reactive oxygen substances generated by living cells as a result of physiological and biochemical processes, and accumulation of these free radicals in neuronal cells against hydrogen peroxide induced toxicity in part by virtue of their antioxidant and free radical scavenging activities (Akram and Nawaz, 2017; Katekhaye et al., 2011). Celastrus paniculatus increases cholinergic activity that contributes its ability to improving memory performance (Akram and Nawaz, 2017; Bhanumathy et al., 2010). It prevented neuronal cell damage against hydrogen peroxide toxicity due to its antioxidant activity (Godkar et al., 2006). Administration of Celastrus paniculatus prevents neuronal cell damage caused by glutamine induced toxicity (Akram and Nawaz, 2017; Godkar et al., 2003). Aqueous extract of Celastrus paniculatus has antioxidant and cognition enhancing properties (Akram and Nawaz, 2017; Kumar and Gupta, 2002).

\section{5) Glycyrrhiza glabra (Yastimadhuka, or Atimaddhura in Kannada)}

Glycyrrhiza glabra is an old age medicinal plant that belongs to Leguminosae/ Fabaceae/ Papilionaceae family and commonly known as mulaithi in north India (Chakravarthi et al., 2013; Pastorino et al., 2018; Dhingra et al., 2004; Sharma and Agrawal, 2013; Obolentseva et al., 1999). Traditionally, Glycyrrhiza glabra has been used to enhance cognitive functions and to alleviate other functions associated with Alzheimer's disease (Chakravarthi et al., 2013; Pastorino et al., 2018; Dhingra et al., 2004; Sharma and Agrawal, 2013; Obolentseva et al., 1999). In the traditional system of medicine, the roots and rhizomes 
the body can cause oxidative damage to lipids, proteins, and DNA, which may lead to cancer, diabetes, aging, and other neurodegenerative diseases (Chakravarthi et al., 2013; Pastorino et al., 2018; Dhingra et al., 2004; Sharma and Agrawal, 2013; Obolentseva et al., 1999). Age, oxidative stress, harmful free radicals, and inflammation are all the key components in the development of memory impairment, including the conditions such as dementia, schizophrenia, and Alzheimer's disease (Chakravarthi et al., 2013; Pastorino et al., 2018; Dhingra et al., 2004; Sharma and Agrawal, 2013; Obolentseva et al., 1999).

Thus, the memory-enhancing activity of aqueous root extract of Glycyrrhiza glabra may be mediated by its antioxidant and anti-inflammatory activities, by virtue of which susceptible brain cells get exposed to less oxidative stress resulting in reduced brain damage and improved neuronal function (Chakravarthi et al., 2013; Pastorino et al., 2018; Dhingra et al., 2004; Sharma and Agrawal, 2013; Obolentseva et al., 1999). Nootropics are used as smart drugs, memory enhancers, neuro enhancers, cognitive enhancers. They may act by improving the availability of neurotransmitters, enzymes, and hormones, improving brain's oxygen supply, or by stimulating nerve growth (Chakravarthi et al., 2013; Pastorino et al., 2018; Dhingra et al., 2004; Sharma and Agrawal, 2013; Obolentseva et al., 1999). Alzheimer's disease is characterized by neuronal loss and the presence of extracellular senile plaques, whose major constituent is amyloid- $\beta$ peptide $(A \beta)$. In one of the study, demonstrated the effects of a water extract of licorice (Yashti-madhuka) on $\mathrm{A} \beta$ 25-35-induced apoptosis in PC12 cells (Chakravarthi et al., 2013; Pastorino et al., 2018; Dhingra et al., 2004; Sharma and Agrawal, 2013; Obolentseva et al., 1999). Results evidenced that Glycyrrhiza glabra exerts a protective effect against apoptotic neuronal cell death induced by A $\beta$ fragments (Chakravarthi et al., 2013; Pastorino et al., 2018; Dhingra et al., 2004; Sharma and Agrawal, 2013; Obolentseva et al., 1999). Extract from the licorice root is reported to treat or even prevent brain cell death in diseases like Alzheimer's and its associated symptoms (Chakravarthi et al., 2013; Pastorino et al., 2018; Dhingra et al., 2004; Sharma and Agrawal, 2013; Obolentseva et al., 1999). Experimental data demonstrated that the memory enhancement effects of Glycyrrhiza glabra may be mediated by its antioxidant and anti-inflammatory activities. Thus, Glycyrrhiza glabra appears to be a promising drug for improving memory in the management of impaired learning, dementia, Alzheimer's disease, and other neurodegenerative disorders (Chakravarthi et al., 2013; Pastorino et al., 2018; Dhingra et al., 2004; Sharma and Agrawal, 2013; Obolentseva et al., 1999).

\section{6) Galanthus nivalis L. (common snowdrop)}

Galanthus is an important genus of the Amaryllidaceae family and the species are native to many parts of Europe including Bulgaria, the eastern parts of Turkey, the Caucasus Mountain and Iran (Salehi Sourmaghi et al., 2010; Heinrich and Teoh, 2004; Bubeva-Ivanova, 1957). The majority of alkaloids especially isoquinoline type like as galanthamine, lycorine, caranine, narciclasine, tazettine, narwedine and montanine which have a wide range of acetylcholinesterase inhibitory, antitumor, antiviral, immunostimulatory and antimalarial activities, have been isolated from this genus species (Rainer, 1997; Heinrich and Teoh, 2004; Salehi Sourmaghi et al., 2010; Rockwood et al., 2001; Fulton and Benfield, 1996; Kewitz, 1997; Harvey, 1995; Bickel, 1991; Dal-Bianco et al., 1991; BubevaIvanova, 1957; Erkinjunti et al., 2002; Farlow, 2001; Parys, 1998). This narrow-leaved snowdrop, with its delicate white hanging flowers, has become very popular in cultivation and is commonly planted in gardens and parks (Bubeva-Ivanova, 1957; Salehi Sourmaghi et al., 2010; Heinrich and Teoh, 2004).

The chief chemical constituent of the Galanthus nivalis (common snowdrop) is galanthamine, and this is an isoquinoline alkaloid (Salehi Sourmaghi et al., 2010; Heinrich and Teoh, 2004; Bubeva-Ivanova, 1957). Acetylcholinesterase inhibitors, which are also called 'anticholinesterase drugs', have been recently approved as an promising treatment approach for Alzheimer's disease (Rainer, 1997; Heinrich and Teoh, 2004; Salehi Sourmaghi et al., 2010; Rockwood et al., 2001; Fulton and Benfield, 1996; Kewitz, 1997; Harvey, 1995; Bickel, 1991; Dal-Bianco et al., 1991; Bubeva-Ivanova, 1957; Erkinjunti et al., 2002; Farlow, 2001; Parys, 1998).

Galanthamine provides an effective symptomatic treatment for patients with Alzheimer's disease. At the same time, it also enables a delay in the progression of the disease (Rainer, 1997; Heinrich and Teoh, 2004; Salehi-Sourmaghi et al., 2010; Rockwood et al., 2001; Fulton and Benfield, 1996; Kewitz, 1997; Harvey, 1995; Bickel, 1991; Dal-Bianco et al., 1991; BubevaIvanova, 1957; Erkinjunti et al., 2002; Farlow, 2001; 
Parys, 1998). Galanthamine, the most important alkaloid, is a long acting, competitive and reversible acetylcholinesterase inhibitor for mid-to-moderate Alzheimer's disease (Rainer, 1997; Heinrich and Teoh, 2004; Salehi-Sourmaghi et al., 2010; Rockwood et al., 2001; Fulton and Benfield, 1996; Kewitz, 1997; Harvey, 1995; Bickel, 1991; Dal-Bianco et al., 1991; Bubeva-Ivanova, 1957; Erkinjunti et al. 2002; Farlow, 2001; Parys, 1998). Narwedine, the biogenetic precursor of galanthamine, has been used as a respiratory stimulant (Salehi- Sourmaghi et al., 2010). It inhibits the action of narcotics and hypnotics and enhances the analgesic activity of morphine as well as the pharmacological effects of caffeine, carbazole, arecoline and nicotine (Salehi Sourmaghi et al., 2010). Lycorine, has appreciable acetylcholinesterase inhibitory activity (Salehi Sourmaghi et al., 2010). It is an analgesic, like aspirin, and has hypotensive activity. Additionally, lycorine has antiviral, antitumor, antimalarial, antiinflammatory, antiplatelet, emetic and cytotoxic activities (Salehi Sourmaghi et al., 2010). Caranine, another lycorine type alkaloid, is a hypotensive which also has shown acetylcholinesterase activity (Salehi Sourmaghi et al., 2010). Tazettine is mildly active against certain tumor cell lines, it also displays weak hypotensive and antimalarial activities and it has been reported as an extraction artifact from pretazettine (Rainer, 1997; Heinrich and Teoh, 2004; Salehi Sourmaghi et al., 2010; Rockwood et al., 2001; Fulton and Benfield, 1996; Kewitz, 1997; Harvey, 1995; Bickel, 1991; Dal-Bianco et al., 1991; Bubeva-Ivanova, 1957; Erkinjunti et al., 2002; Farlow, 2001; Parys, 1998).

In recent years, galanthamine isolated from several members of the Amaryllidaceae (Leucojum spp., Narcissus species, Galanthus spp.) has become an important therapeutic options used to slow down the process of neurological degeneration in Alzheimer's disease (Rainer, 1997; Heinrich and Teoh, 2004; Salehi Sourmaghi et al., 2010; Rockwood et al., 2001; Fulton and Benfield, 1996; Kewitz, 1997; Harvey, 1995; Bickel, 1991; Dal-Bianco et al., 1991; Bubeva-Ivanova, 1957; Erkinjunti et al., 2002; Farlow, 2001; Parys, 1998). The development of galanthamine (galantamine), a drug commonly used today in the treatment of Alzheimer's disease (Rainer, 1997; Heinrich and Teoh, 2004; Salehi Sourmaghi et al., 2010; Rockwood et al., 2001; Fulton and Benfield, 1996; Kewitz, 1997; Harvey, 1995; Bickel, 1991; Dal-Bianco et al., 1991; Bubeva-Ivanova, 1957; Erkinjunti et al., 2002; Farlow,
2001; Parys, 1998). It is a natural product known from several members of the Amaryllidaceae and the idea for developing a natural product from these species seems to be based on ethnobotanical information (Heinrich and Teoh, 2004; Salehi Sourmaghi et al., 2010; Rainer, 1997; Heinrich and Teoh, 2004; Salehi Sourmaghi et al., 2010; Rockwood et al., 2001; Fulton and Benfield, 1996; Kewitz, 1997; Harvey, 1995; Bickel, 1991; DalBianco et al., 1991; Bubeva-Ivanova, 1957; Erkinjunti et al., 2002; Farlow, 2001; Parys, 1998).

Galanthamine has been found to be the long-acting and specific inhibitor of the acetylcholinesterase enzyme and to potentiate cholinergic nicotinic neurotransmission by allosterically modulating the nicotinic acetylcholine receptors, which may be of additional value in the treatment of Alzheimer's disease (Rainer, 1997; Heinrich and Teoh, 2004; Salehi Sourmaghi et al., 2010; Rockwood et al., 2001; Fulton and Benfield, 1996; Kewitz, 1997; Harvey, 1995; Bickel, 1991; Dal-Bianco et al., 1991; Bubeva-Ivanova, 1957; Erkinjunti et al., 2002; Farlow, 2001; Parys, 1998).

\section{7) Huperzia serrata (Toothed firmoss)}

Huperzia serrata (Thunb. ex Murray) Trevis is commonly known as toothed firmoss is widely distributed species of clubmoss belongs to the family Lycopodiaceae. It contains a large group of alkaloids called Lycopodium alkaloids (Chang et al., 2016; Jaswinder et al., 2016; Patocka, 1998; Jun, 2008; Bai et al., 2000; Liu et al., 1986). It is a terrestrial plant mainly found in India, China, Nepal, Myanmar, Sri Lanka, Japan, Korea, Vietnam, Indonesia, Fiji, Samoa, Mexico, USA, Thailand, Peninsular Malaysia, Russia, Taiwan, Australia and Cuba (Chang et al., 2016; Jaswinder et al., 2016; Patocka, 1998; Jun, 2008; Bai et al., 2000; Liu et al., 1986). It is a traditional Chinese remedy which is also known as Qian Ceng Ta (Chang et al., 2016; Jaswinder et al., 2016; Patocka, 1998; Jun, 2008; Bai et al., 2000; Liu et al., 1986). Chinese scientists Liu and his co-worker had discovered Huperzine A, and Huperzine-B which were known as a worldwide medicine (Liu et al., 1986). HuperzineA is an alkaloid which can be isolated from whole plant of the Huperzia serrata (Liu et al., 1986). HuperzineA is really more a drug than an herb; it is sold as a dietary supplement for memory loss and mental impairment. Huperzine A drug has been shown antioxidant and neuroprotective properties (Chang et al., 2016; Jaswinder et al., 2016; 
Patocka, 1998; Jun, 2008; Bai et al., 2000; Liu et al., 1986). Pharmacological activities such as anticonvulsant, anti-inflammatory, anti-nociception, alzheimer, schizophrenia, anti-apoptosis effect, organophosphate poisoning myasthenia gravis, antioxidant and protection of mitochondria (Chang et al., 2016; Jaswinder et al., 2016; Patocka, 1998; Jun, 2008; Bai et al., 2000; Liu et al., 1986).

Huperzia serrata has a long history in Chinese medicine for use in conditions including strains, swellings, schizophrenia, myasthenia gravis, and organophosphate poisoning (Chang et al., 2016; Jaswinder et al., 2016; Patocka, 1998; Jun, 2008; Bai et al., 2000; Liu et al., 1986). The key bioactive components of Huperzia serrata belong to the lycopodium alkaloids family including huperzine $\mathrm{A}$, huperzine $\mathrm{B}$, hyperzinine, carinatumin $\mathrm{A}$, and carinatumin $\mathrm{B}$, all of which possess anti-acetylcholinesterase properties (Chang et al., 2016). In particular, Huperzine A, became known globally after the discovery in the 1980s for its use as a potent acetylcholinesterase inhibitor in the treatment of dementia (Chang et al., 2016). The clinical results demonstrated that Huperzine A, (300-500 g/day) significantly improves cognitive function, as assessed by the mini-mental state examination (MMSE) and daily activities of adults (Chang et al., 2016; Jaswinder et al., 2016; Patocka, 1998; Jun, 2008; Bai et al., 2000; Liu et al., 1986). Huperzine A is isolated from Chinese herb Huperzia serrata having some properties that can treat the Alzheimer's disease. Huperzine A has some beneficial effects which improving global clinical status, general cognitive function, behavioural disturbance and functional performances in Alzheimer's disease (Chang et al., 2016; Jaswinder et al., 2016; Patocka, 1998; Jun, 2008; Bai et al., 2000; Liu et al., 1986).

Several studies indicate that the Huperzine A effective against the reduced acetylcholine levels in the brain and glutamate induced neuronal death, which the most neuronal disorders are observed in Alzheimer's disease (Chang et al., 2016; Jaswinder et al., 2016; Patocka, 1998; Jun, 2008; Bai et al., 2000; Liu et al., 1986). The effects of Huperzine A on memory disorder in schizophrenic patients have been studied (Chang et al., 2016; Jaswinder et al., 2016; Patocka, 1998; Jun, 2008; Bai et al., 2000; Liu et al., 1986). In all those studies the memory functions of patients were significantly improved after the treatment with Huperzine A (Chang et al., 2016; Jaswinder et al., 2016; Patocka, 1998; Jun, 2008; Bai et al., 2000; Liu et al., 1986). The potential of
Huperzine $\mathrm{A}$ as add-on therapy in schizophrenic patients who did not obtain satisfactory response to antipsychotic treatment demonstrated the beneficial effect of Huperzine A in treating cognitive and negative symptom clusters of schizophrenia over twelve weeks (Chang et al., 2016; Jaswinder et al., 2016; Patocka, 1998; Jun, 2008; Bai et al., 2000; Liu et al., 1986).

\section{8) Panax Ginseng}

Panax ginseng, also called Asian or Korean ginseng, has long been traditionally used in Korea and China to treat various diseases(Chuang et al., 2008; Choi et al., 2010; Radad et al., 2006; Chu et al., 2014; Chang et al., 2016). The major active ingredients of Panax ginseng are ginsenosides, which have been shown to have a variety of therapeutic effects, including antioxidation, anti-inflammatory, vasorelaxation, antiallergic, antidiabetic, and anticancer (Chuang et al., 2008; Choi et al., 2010; Radad et al., 2006; Chu et al., 2014; Chang et al., 2016). Ginseng belongs to the family Araliaceae has shown therapeutic benefits for learning and memory and may be useful in developing supplements for the prevention or potential treatment of Alzheimer's disease (Chang et al., 2016). The principal bioactive components of ginseng are ginsenosides (e.g., ginsenosides $\mathrm{Rg} 1, \mathrm{Rg} 3$, and $\mathrm{Rg} 5$ ), which have been suggested to have antioxidant, antiinflammatory, and antiapoptotic effects. Panax ginseng (Ren Shen) and Panax notoginseng (San Qi) are two important members of the ginseng species and have been used for centuries in Chinese medicine to treat atherosclerosis, hypertension, thrombosis, external injury, and pain (Chang et al., 2016). Ginseng is widely used to treat dementia-like symptoms in many Asian countries; however the majority of studies examining its effects on cognition have been studied in animals and healthy individuals (Chuang et al., 2008; Choi et al., 2010; Radad et al., 2006; Chu et al. 2014; Chang et al. 2016). Clinical trial data demonstrated that ginseng modestly improves thinking and working memory in healthy volunteers (Chuang et al., 2008; Choi et al., 2010; Radad et al., 2006; Chu et al., 2014; Chang et al., 2016). Research has also suggested that ginseng is able to enhance the psychomotor and cognitive performance, and can benefit Alzheimer's disease by improving the brain cholinergic function, reducing the level of Alzheimer's disease and repairing the damaged neuronal networks (Chuang et al., 2008; Choi et al., 2010; Radad et al., 2006; Chu et al., 2014; Chang et al., 2016). 


\section{9) Emblica officinalis (Amla)}

Emblica officinalis belongs to the family Euphorbiaceae. The Indian gooseberry, or 'aamla', is a deciduous tree of the Phyllanthaceae family. It exhibited significant improvement in memory retention. Emblica officinalis plays an important role in the treatment of memory deficits and Alzheimer's disease (Mani et al., 2007; Ramachandran et al., 2013; Rao et al., 2012; Gulkari and Maske, 2020; Rajagopal et al., 2013).

\section{0) Evolvulus alsinoides}

Evolvulus alsinoides belongs to the family Convolvulaceae. Nahata et al. (2010) reported the efficacy of Evolvulus alsinoides in learning behavior and memory enhancement activity in rodents (Akram and Nawaz, 2017; Nahata et al., 2010). Evolvulus alsinoides extracts significantly enhanced learning ability and memory retention in rats. Furthermore, these extracts $\quad(0.3 \mathrm{mg} / \mathrm{kg}, \quad$ i.p $)$ significantly reversed scopolamine induced amnesia in rats (Akram and Nawaz, 2017; Nahata et al., 2010). Nootropic activity of Evolvulus alsinoides extracts was compared with piracetam as the standard drug. Extract showed significant memory enhancing activity in the step-down and shuttle-box avoidance paradigms (Akram and Nawaz, 2017; Nahata et al., 2010).

\section{1) Withania somnifera (Ashwagandha)}

Withania somnifera (L.) Dunal belongs to the family Solanaceae, popularly known as 'Ashwagandha' and as 'Indian ginseng' (Sehgal et al., 2012; Pingali et al., 2014; Bhatnagar et al., 2009; Kulkarni and Dhir, 2008; Shahriar et al., 2014; Kumar et al., 2015). Withania somnifera (Ashwagandha) is an important Rasayana herb and widely considered as Indian ginseng in Ayurveda (Sehgal et al., 2012; Pingali et al., 2014; Bhatnagar et al., 2009; Kulkarni and Dhir, 2008; Shahriar et al., 2014; Kumar et al., 2015). It is a green woody shrub of $200-800 \mathrm{~cm}$ height, found throughout the drier parts of South East Asia including India, Bangladesh, Sri-Lanka, Nepal and Pakistan, and different other parts of Australia, Africa and America (Sehgal et al., 2012; Pingali et al., 2014; Bhatnagar et al., 2009; Kulkarni and Dhir, 2008; Shahriar et al., 2014; Kumar et al., 2015). In traditional system of Indian medicine, it is used as tonic to rejuvenate the body and increase longevity. In Ayurvedic preparations, various parts of the plant have been used to treat variety of ailments that affect the human health (Sehgal et al., 2012; Pingali et al., 2014; Bhatnagar et al., 2009; Kulkarni and Dhir, 2008; Shahriar et al., 2014; Kumar et al., 2015). However, dried roots of the plant are widely used for the treatment of nervous and sexual disorders (Kumar et al., 2015). The major active chemical constituents of this plant are withanolides, which is responsible for its wide range of biological activities (Sehgal et al., 2012; Pingali et al., 2014; Bhatnagar et al., 2009; Kulkarni and Dhir, 2008; Shahriar et al., 2014; Kumar et al., 2015). Ashwagandha is also reported as a nervine tonic that rejuvenates the cells and boosts energy (Sehgal et al., 2012; Pingali et al., 2014; Bhatnagar et al., 2009; Kulkarni and Dhir, 2008; Shahriar et al., 2014; Kumar et al., 2015). Preclinical research and clinical trials demonstrated the use of Withania somnifera for the treatment of neurological conditions such as anxiety, depression, cognitive disorders, senile dementia and neurodegenerative disorders (Alzheimer's and Parkinson's) (Sehgal et al., 2012; Pingali et al., 2014; Bhatnagar et al., 2009; Kulkarni and Dhir, 2008; Shahriar et al., 2014; Kumar et al., 2015).

Active glycowithanolides of Withania somnifera (Ashawgandha) have a significant antioxidant function, which is accomplished by increasing the activities of superoxide dismutase, catalase, and glutathione peroxidase (Sehgal et al., 2012; Pingali et al., 2014; Bhatnagar et al., 2009; Kulkarni and Dhir, 2008; Shahriar et al., 2014; Kumar et al., 2015). Withania somnifera was also found to improve the cognitive capabilities of the brain by increasing the cortical muscarinic acetylcholine capacity in lateral septum and frontal cortex, which suggest their capacity to affect events in the cortical cholinergic-signal transduction cascade (Sehgal et al., 2012; Pingali et al., 2014; Bhatnagar et al., 2009; Kulkarni and Dhir, 2008; Shahriar et al., 2014; Kumar et al., 2015). One such report has revealed that, Withania somnifera root extract down-regulates nitric oxide production that significantly inhibits the stress induced NADPH-diaphorase activation in the brain via suppressing corticosterone release and activating cholineacetyltransferase (Kumar et al., 2015). This pathway is thought to be the main mechanism underlying the neuroprotective effects of Withania somnifera (Sehgal et al., 2012; Pingali et al., 2014; Bhatnagar et al., 2009; Kulkarni and Dhir, 2008; Shahriar et al., 2014; Kumar et al., 2015). The results of the various findings described that, Withania 
somnifera and its chemical ingredients are effective in prevention of neurodegenerative disorders and protect neurons from oxidative damages (Sehgal et al., 2012; Pingali et al., 2014; Bhatnagar et al., 2009; Kulkarni and Dhir, 2008; Shahriar et al., 2014; Kumar et al., 2015). The assessment of cholinesterase inhibition was carried out using a colorimetric method based on Ellman's reaction and demonstrated that the Withania somnifera extract significantly inhibited acetylcholinesterase in a concentration-dependent manner (Sehgal et al., 2012; Pingali et al., 2014; Bhatnagar et al., 2009; Kulkarni and Dhir, 2008; Shahriar et al., 2014; Kumar et al., 2015).

\section{2) Urtica dioica L. (Stinging nettle)}

Urtica dioica $L$ is commonly known as stinging nettle belongs to the family Urticaceae. Nettles contain a significant number of biologically-active compounds (Kregiel et al., 2018; Singhal et al., 2012; Keyvan et al., 2007). Nettles are one of the most commonly-used medicinal plants in the world, due to their healthenhancing qualities. The genus Urtica belongs to the family Urticaceae in the major group Angiosperms (flowering plants) and there are 46 species of flowering plant of the genus Urtica (Kregiel et al., 2018; Singhal et al., 2012; Keyvan et al., 2007). The most prominent members of the genus are the stinging nettle Urtica dioica L (Kregiel et al., 2018; Singhal et al., 2012; Keyvan et al., 2007). Nettles grow all over the world in mild to temperate climates. Plant hairs located on the leaves and stems contain a number of chemicals, which can cause a stinging reaction and uncomfortable irritation when brought into contact with human skin ((Kregiel et al., 2018; Singhal et al., 2012; Keyvan et al., 2007). Most nettle medicines are made from the flowers, stems and leaves, but roots are also used in pharmacology (Kregiel et al., 2018; Singhal et al., 2012; Keyvan et al., 2007).

Urtica dioica $\mathrm{L}$. has been used most commonly as a diuretic and for treating painful muscles and joints, eczema, gout and anemia. Urtica dioica L may be used as a vegetable, in juice, tea and as an ingredient in many dishes (Kregiel et al., 2018; Singhal et al., 2012; Keyvan et al., 2007). The use of Urtica spp. as a feed component could also positively affect the health of poultry and animal productivity (Kregiel et al., 2018; Singhal et al., 2012; Keyvan et al., 2007). These properties make nettles suitable for a range of possible applications, including functional food, dietary supplements and pharmacological formulations (Kregiel et al., 2018; Singhal et al., 2012; Keyvan et al., 2007). Stinging nettle has also been shown to elevate the mood in some Alzheimer's patients (Kregiel et al., 2018; Singhal et al., 2012; Keyvan et al., 2007).

\section{3) Myristica fragrans}

Myristica fragrans belongs to the family Myristicaceae. Myristica fragrans is used in nervous disorders, digestive disorders, leukemia, bodyache, vomiting, tachycardia, dizziness and memory disturbances (Akram and Nawaz, 2017; Asgarpanah and Kazemivash, 2012; Maeda et al., 2008; Narasimhan and Dhake, 2006). N-hexane extract of Myristica fragrans was found effective at $5 \mathrm{mg} / \mathrm{kg}$ in reversing scopolamine and diazepam induced impairment in learning and memory (Akram and Nawaz, 2017; Parle et al., 2004). This study validated the use of Myristica fragrans in the management of Alzheimer's disease and memory deficits (Akram and Nawaz, 2017; Parle et al., 2004).

\section{4) Ilex paraguariensis}

Ilex paraguariensis belongs to the family Aquifoliaceae. It has a memory enhancing property and effective in the treatment of neurodegenerative disorders such as Alzheimer's disease (Bastos et al., 2007; Colpo et al., 2007; Rui et al., 2008; Heck et al., 2007; Rao et al., 2012; Gulkari and Maske, 2020; Rajagopal et al., 2013).

\section{5) Acorus calamus L. (Vacha)}

Vacha (Acorus calamus L.) belongs to family Acoraceae is a traditional Indian medicinal fragrant herb, which is practiced to treat a wide range of health ailments, insomnia, melancholia, epilepsy, hysteria, remittent fevers, including neurological, gastrointestinal, respiratory, metabolic, kidney, and liver disorders (Sharma et al., 2020; Sharma et al., 2014; Singh et al., 2011; Shukla et al., 2006; Esfandiari et al., 2018; Heneka and O'Banion, 2007; Hardy and Selkoe, 2002; Nunomura et al., 2006; Balakumbahan et al., 2010). Acorus calamus rhizomes and leaves are also used as an active pharmaceutical ingredient in various Ayurvedic formulations (Sharma et al., 2020; Sharma et al., 2014; Singh et al., 2011; Shukla et al., 2006; Esfandiari et al., 2018; Heneka and O'Banion, 2007; Hardy and Selkoe, 2002; Nunomura et al., 2006; Balakumbahan et al., 2010). Compelling in vitro, in vivo and clinical evidences demonstrated that the potential 
role of Acorus calamus rhizomes for modulating metabolic and neurological disorders could be due to their richness in several classes of active phytoconstituents (Sharma et al., 2020; Sharma et al., 2014; Singh et al., 2011; Shukla et al., 2006; Esfandiari et al., 2018; Heneka and O'Banion, 2007; Hardy and Selkoe, 2002; Nunomura et al., 2006; Balakumbahan et al., 2010). Some studies revealed antioxidant properties of Acorus calamus is used as memory enhancer (Sharma et al., 2020; Sharma et al., 2014; Singh et al., 2011; Shukla et al., 2006; Esfandiari et al., 2018; Heneka and O'Banion, 2007; Hardy and Selkoe, 2002; Nunomura et al., 2006; Balakumbahan et al., 2010). Due to the presence of alpha- and beta-asarone, Acorus calamus is endowed with anti-inflammatory properties which reduce inflammatory cytokines (Sharma et al., 2020; Sharma et al., 2014; Singh et al., 2011; Shukla et al., 2006; Esfandiari et al., 2018; Heneka and O'Banion, 2007; Hardy and Selkoe, 2002; Nunomura et al., 2006; Balakumbahan et al., 2010).

Acorus calamus (sweet flag) demonstrated a beneficial memory enhancing property for memory impairment, learning performance, behavior modification, and inhibits the acetylcholinesterase (Sharma et al., 2020; Sharma et al., 2014; Singh et al., 2011; Shukla et al., 2006; Esfandiari et al., 2018; Heneka and O'Banion, 2007; Hardy and Selkoe, 2002; Nunomura et al., 2006; Balakumbahan et al., 2010). Acorus calamus contains a majority of $\alpha$-and $\beta$-asarone. In the Ayurveda medicine system, Acorous calamus has been used for the treatment of memory loss and its related symptoms (Sharma et al., 2020; Sharma et al., 2014; Singh et al., 2011; Shukla et al., 2006; Esfandiari et al., 2018; Heneka and O'Banion, 2007; Hardy and Selkoe, 2002; Nunomura et al., 2006; Balakumbahan et al., 2010). Neuroinflammation is a neurological disorder that could lead to neurodegenerative diseases. Alzheimer's disease is one of the most common neurodegenerative diseases and one of the most common causes of mental decline in healthy people. Pathological signs of Alzheimer's disease include accumulation of beta-amyloid plaques in and out of the neurons and the formation of neurofibrillary tangles within the neuronal cell made by Tau proteins (Sharma et al., 2020; Sharma et al., 2014; Singh et al., 2011; Shukla et al., 2006; Esfandiari et al., 2018; Heneka and O'Banion, 2007; Hardy and Selkoe, 2002; Nunomura et al., 2006; Balakumbahan et al., 2010).

Several factors lead to memory loss, the most important of which is brain aging that is caused mostly by neuroinflammation and oxidative stress. The oral administration of different fractions of Acorus calamus, especially aqueous fraction, prevented from memory deficits and stress through controlling oxidative stress and inflammation processes (Sharma et al., 2020; Sharma et al., 2014; Singh et al., 2011; Shukla et al., 2006; Esfandiari et al., 2018; Heneka and O'Banion, 2007; Hardy and Selkoe, 2002; Nunomura et al., 2006; Balakumbahan et al., 2010). In one of the study demonstrated that different fractions of Acoru calamus are dose-dependently effective in preventing memory impairment and stress development through controlling oxidative stress and inflammation (Sharma et al., 2020; Sharma et al., 2014; Singh et al., 2011; Shukla et al., 2006; Esfandiari et al., 2018; Heneka and O'Banion, 2007; Hardy and Selkoe, 2002; Nunomura et al., 2006; Balakumbahan et al., 2010). There is also evidence which proposes that beta-amyloid and Tau protein accumulation constitute compensatory response to oxidative stress. It is found that oxidative stress causes behavioral and memory impairment (Sharma et al., 2020; Sharma et al., 2014; Singh et al., 2011; Shukla et al., 2006; Esfandiari et al., 2018; Heneka and O'Banion, 2007; Hardy and Selkoe, 2002; Nunomura et al., 2006; Balakumbahan et al., 2010). Moreover, studies have also revealed that oxidative stress and neuroinflammation induce stress and anxiety disorder. In addition, in some studies, neuroinflammation is considered as a leading cause of initiating pathological symptoms of Alzheimer's disease (beta-amyloid and Tau protein) (Sharma et al., 2020; Sharma et al., 2014; Singh et al., 2011; Shukla et al., 2006; Esfandiari et al., 2018; Heneka and O'Banion, 2007; Hardy and Selkoe, 2002; Nunomura et al., 2006; Balakumbahan et al., 2010).

\section{6) Commiphora whighitti (Arn.) Bhandari}

Commiphora whighitti belongs to the family Burseraceae. It is a potent cognition enhancer for memory improvement in scopolamine induced memory deficits (Gujran et al., 2007). Commiphora whighitti acts on impairment in learning and memory and decreased choline actyl transferase levels in hippocampus (Gujran et al., 2007; Lannert and Hoyer, 1998; Akram and Nawaz, 2017; Raja and Hoyer, 2004). However, Commiphora whighitti shows maximum effects on memory functions and the potential for dementia disorder (Gujran et al., 2007; Lannert and Hoyer, 1998; Akram and Nawaz, 2017; Raja and Hoyer, 
2004). Another study shows that brain pathology developed in cholesterol fed rabbits similar to Alzheimer's disease (Gujran et al., 2007; Lannert and Hoyer, 1998; Akram and Nawaz, 2017; Raja and Hoyer, 2004) which is supported by clinical trials in human, showing that statin treatment decreases the risk of Alzheimer's disease (Raja and Hoyer, 2004). Memory enhancing and anti-dementia activity of Commiphora whighitti has been reported that is due to reduction in acetylcholinesterase contents in the hippocampus (Lannert and Hoyer, 1998). Commiphora whighitti (Guggulu), a plant resin, contains the major constituent of guggulipid, which is guggulsterone (Gujran et al., 2007; Lannert and Hoyer, 1998; Akram and Nawaz, 2017; Raja and Hoyer, 2004). The guggulipid has been seen to be a potential cognitive enhancer for improvement of memory in scopolamine-induced memory deficits (Gujran et al., 2007; Lannert and Hoyer, 1998; Akram and Nawaz, 2017; Raja and Hoyer, 2004).

\section{7) Convolvulus pluricaulis (Shankhpushpi)}

Convolvulus pluricaulis belongs to the family Convolvulaceae known for memory enhancing property which calm the nerves by regulating the stress hormones synthesis (cortisol and adrenaline) in the body (Akram and Nawaz, 2017; Sethiya et al., 2009). Clinical experiments demonstrated that aqueous and ethyl acetate extract of Convolvulus pluricaulis increased memory functions and learning abilities in rats (Akram and Nawaz, 2017; Bihaqi et al., 2011; Nahata et al., 2008). Further secondary metabolites of Convolvulus pluricaulis such as steroids, anthocyanins, flavonol glycosides and triterpenoids are responsible for memory enhancing and nootropic properties (Akram and Nawaz, 2017; Malik et al., 2011). Similarly, administration of Convolvulus pluricaulis for 1 week increased memory in aged mice (Akram and Nawaz, 2017; Sharma et al., 2010). Administration of Convolvulus pluricaulis increased the acetyl cholinesterase activity in the hippocampal CA1 and CA3 regions associated with the memory function and learning abilities (Akram and Nawaz, 2017; Dubey et al., 1994).

\section{8) Tinospora cordifolia (Guduchi) (Amruthballi in Kannada)}

Tinospora cordifolia (Guduchi) or Giloy or belongs to the family Menispermaceae. Native to India, it is considered to be a divine herb used in Indian medicine for ages (Kumar et al., 2017). The Ayurvedic herb Guduchi or Giloy (Tinospora Cordifolia) is a powerhouse of antioxidants that neutralise free radicals and prevent inflammation, purifies blood, boosts immunity, flushes out toxins from the body and fights against bacteria and virus effectively (Kumar et al., 2017). Tinospora cordifolia's mechanism for cognitive enhancement is by immunostimulation and synthesis of acetylcholine, this supplementation of choline enhances the cognitive function (Agarwal et al., 2002; Asuthosh et al., 2000; Lannert and Hoyer, 1998; Malve et al., 2014; Tabassum et al., 2012; Akram and Nawaz, 2017). Administration of Tinospora cordifolia increases the cognitive function in patients with Alzheimer's disease (Agarwal et al., 2002; Asuthosh et al., 2000; Lannert and Hoyer, 1998; Malve et al., 2014; Akram and Nawaz, 2017). Pharmacological activities include antifertility, antioxidant and immunomodulating activities (Agarwal et al., 2002; Asuthosh et al., 2000; Lannert and Hoyer, 1998; Malve et al., 2014). Tinospora cordifolia possesses a memory improving effect in animals with memory deficits (Malve et al., 2014; Akram and Nawaz, 2017; Tabassum et al., 2012). The mechanism by which Tinospora cordifolia improves memory is the synthesis of acetylcholine and immunostimulation (Agarwal et al., 2002; Asuthosh et al., 2000; Lannert and Hoyer, 1998; Malve et al., 2014; Akram and Nawaz, 2017).

\section{9) Magnolia officinalis}

Magnolia officinalis belongs to the family Magnoliaceae. Magnolia officinalis plays an important role in the management of Alzheimer's disease and memory deficits (Tabassum et al., 2012; Jie et al., 2000; Chen et al., 2001; Liou et al., 2003; Akram and Nawaz, 2017). Magnolia officinalis inhibits acetylcholinesterase activity (Jae et al., 2009). Magnolia Officinalis inhibits the memory impairment induced by scopolamine through the inhibition of acetyl cholinesterase activity. Biphenolic lignins (magnolol and honokiol) derived from Magnolia officinalis, have the ability to enhance the choline acetyltransferase effects and inhibit the acetylcholine cleavage and have also been shown to release acetylcholine from the hippocampus (Tabassum et al., 2012; Kong et al., 2000; Chen et al., 2001; Liou et al., 2003; Jae et al., 2009; Lee et al., 2009; Hou et al., 2000; Wang et al., 1992; Akram and Nawaz, 2017). The ethanolic extracts of $M$. officinalis reported to have antioxidant activity in vitro and in vivo. Magnolol 
showed in vitro neuroprotective activity and compound also exhibited anti-inflammatory effect in vivo and in vitro (Tabassum et al., 2012; Kong et al., 2000; Chen et al., 2001; Liou et al., 2003; Jae et al., 2009; Lee et al., 2009; Hou et al., 2000; Wang et al., 1992; Akram and Nawaz, 2017).

Magnolol, honokiol, and obovatol are well-known bioactive constituents of the bark of Magnolia officinalis and have been used as traditional Chinese medicines for the treatment of neurosis, anxiety, and stroke (Tabassum et al., 2012; Kong et al., 2000; Chen et al., 2001; Liou et al., 2003; Jae et al., 2009; Lee et al., 2009; Hou et al., 2000; Wang et al., 1992; Akram and Nawaz, 2017). A study also has suggested that the ethanol extract of Magnolia officinalis and its major ingredient, 4-O-methylhonokiol, may be useful for the prevention of the development or progression of Alzheimer's disease (Tabassum et al., 2012; Kong et al., 2000; Chen et al., 2001; Liou et al., 2003; Jae et al., 2009; Lee et al., 2009; Hou et al., 2000; Wang et al., 1992; Akram and Nawaz, 2017). Cognitive enhancers are drugs, supplements, nutraceuticals and functional foods that are purported to improve mental functions such as cognition, memory, intelligence, motivation, attention and concentration (Tabassum et al., 2012; Kong et al., 2000; Chen et al., 2001; Liou et al., 2003; Jae et al., 2009; Lee et al., 2009; Hou et al., 2000; Wang et al., 1992; Akram and Nawaz, 2017).

The bark of Magnolia Officinalis (talauma) is used as a traditional memory enhancing agent in Chinese medicine for the treatment of neurosis, anxiety, stroke, and dementia. It improves the scopolamine induced memory deficits (Tabassum et al., 2012; Kong et al., 2000; Chen et al., 2001; Liou et al., 2003; Jae et al., 2009; Lee et al., 2009; Hou et al., 2000; Wang et al., 1992; Akram and Nawaz, 2017).

Ethanolic extract of Magnolia officinalis containing honokiol and magnolol has been reported to possess antioxidant effects (Tabassum et al., 2012; Kong et al., 2000; Chen et al., 2001; Liou et al., 2003; Jae et al., 2009; Lee et al., 2009; Hou et al., 2000; Wang et al., 1992; Akram and Nawaz, 2017). Both compounds exhibited in vivo antioxidant and anti-inflammatory activity effects by inhibiting reactive oxygen species synthesis (Tabassum et al., 2012; Kong et al., 2000; Chen et al., 2001; Liou et al., 2003; Jae et al., 2009; Lee et al., 2009; Hou et al., 2000; Wang et al., 1992; Akram and Nawaz, 2017).

\section{0) Collinsonia canadensis (Horsebalm)}

Collinsonia canadensis is a medicinal herbal plant belongs to the family Lamiaceae. The chief chemical constituents of horsebalm are carvacol and thymol which are used for Alzheimer's disease (Gulkari and Maske, 2020; Tabassum et al., 2012; Singhal, 2012; Rajagopal et al., 2013). Horsebalm (Monarda) has been reported to prevent the breakdown of acetylcholine (Gulkari and Maske, 2020; Rajagopal et al., 2013; Singhal, 2012; Akram and Nawaz, 2017; Tabassum et al., 2012). Normally our body's protective blood-brain barrier helps to prevent harmful substances in the blood from reaching the tissues of the brain (Gulkari and Maske, 2020; Rajagopal et al., 2013; Singhal, 2012; Akram and Nawaz, 2017; Tabassum et al., 2012). However, it can also prevent helpful medicines from reaching the brain (Gulkari and Maske, 2020; Singhal, 2012). The horsebalm compounds seem to cross that great divide. Horsebalm is even used as a herbal shampoo by adding a few drops to your normal herbal shampoo (Gulkari and Maske, 2020; Singhal, 2012; Rajagopal et al., 2013; Akram and Nawaz, 2017; Tabassum et al., 2012). The herbs that hinder acetylcholinesterase contain normal COX-2 inhibitors, additionally revealed as restorative herbs, for Alzheimer's disease sign (Rajagopal et al., 2013; Gulkari and Maske, 2020; Singhal, 2012; Tabassum et al., 2012).

\section{1) Lepidium meyenii (Maca)}

Lepidium meyenii Walp is a medicinal plant belongs to family Brassicaceae known for improvement in learning abilities and memory function (Gulkari and Maske, 2020; Rajagopal et al., 2013; Julio et al., 2007). Lepidium meyenii exhibited memory enhancing activity in patients with Alzheimer's disease (Rajagopal et al., 2013; Gulkari and Maske, 2020; Wang et al., 2006). It enhances memory by increasing level of acetylcholine (Wang et al., 2006; Gulkari and Maske, 2020). It improves experimental memory impairment induced by ovariectomy, due in part to its acetylcholinesterase inhibitory and antioxidant effects (Gulkari and Maske, 2020; Julio et al., 2007; Rubio et al., 2011). Results showed that Lepidium meyenii can enhance memory retention and learning abilities in ovariectomized mice and this activity might be related, at least in part, to its ability to decrease lipid peroxidation and acetylcholinesterase in ovariectomized mice (Gulkari and Maske, 2020; Julio et al., 2007; Rubio et al., 2011). 
Lepidium meyenii shows beneficial improvement in memory and learning. Black maca improves experimental memory impairment, induced by ovariectomy, due in part, to its antioxidant and acetylcholinesterase inhibitory activities (Gulkari and Maske, 2020; Julio et al., 2007; Rubio et al., 2011). Results demonstrated that black maca (Lepidium meyenii) can enhance learning and memory in ovariectomized mice and this effect might be related, at least in part, to its ability to reduce lipid peroxidation and acetylcholinesterase in ovariectomized mice (Gulkari and Maske, 2020; Julio et al., 2007; Rubio et al., 2011).

\section{2) Angelica gigas (Nakai Root)}

The genus Angelica L. belongs to the family of Apiaceae (Umbelliferae) that contains about 60 species of biennial or short lived perennial herbs and occurs widely in Asia, Europe and North America (Sowndhararajan and Ki, 2017; Shin and Park, 2014). According to its area of distribution, three common species of Angelica species, Angelica gigas, Angelica sinensis, and Angelica acutiloba, are found in Korea, China and Japan (Sowndhararajan and Ki, 2017; Shin and Park, 2014). Angelica gigas Nakai is an important medicinal plant with health promoting properties that is used to treat many disorders (Sowndhararajan and $\mathrm{Ki}$, 2017). In traditional herbal medicine, the root of this plant is used to promote blood flow, to treat anemia, and is used as sedative or tonic agent (Sowndhararajan and $\mathrm{Ki}, 2017)$.

The published reports revealed that the extracts and isolated components from the root of Angelica gigas showed neuroprotective and cognitive enhancement properties through various mechanisms such as antiapoptosis, antioxidative actions, inhibiting mRNA and protein expressions of inflammatory mediators and regulating a number of signaling pathways (Sowndhararajan and Ki, 2017; Shin and Park, 2014).

Recently, several in vitro and in vivo studies have reported that the crude extracts and isolated components from the root of Angelica gigas exhibited neuroprotective and cognitive enhancement effects (Sowndhararajan and Ki, 2017; Shin and Park, 2014). Neuronal damage or death is the most important factor for many neurodegenerative diseases (Sowndhararajan and Ki, 2017; Shin and Park, 2014). In addition, recent studies have clearly demonstrated the possible mechanisms behind the neuroprotective action of extracts/compounds from the root of Angelica gigas (Sowndhararajan and Ki, 2017; Shin and Park, 2014).

\section{3) Angelica archangelica (Dudhachoraa, Laghu Coraka)}

Angelica archangelica $\mathrm{L}$. is a medicinal plant belgons to the family Apiaceae (Singhal et al., 2012). Angelica archangelica is also commonly known as garden angelica, wild celery, and Norwegian angelica or also known as Dudhachoraa (Laghu Coraka), contains several substances that have the same kind of activity as drugs used for Alzheimer's disease (Singhal et al., 2012). These substances do not cause the side effects observed with drugs, such as, nausea, stomach ache, insomnia, and so on (Singhal et al., 2012). The same phytochemicals in Angelica archangelica can also increase blood flow in the brain. A study shows that chloromethane sub-fraction of a methanol extract inhibit acetylcholinesterase in-vitro (Singhal et al., 2012).

\section{4) Bertholettia excelsa (Lecythidaceae)}

Brazil nut (Bertholletia excelsa Humb. \& Bonpl.) is a medicinal Amazonian plant species and an important resource for local populations (Takeuchi and Egea, 2020; Singhal et al., 2012; Santos et al., 2013; Keyvan et al., 2007) The Bertholletia excelsa Bonpl. seed, Brazil nut, is one of the most important non-timber forest products in the Amazon forest (Takeuchi and Egea, 2020; Singhal et al., 2012; Santos et al., 2013; Keyvan et al. 2007). Brazil nut's nutritious, oil-rich seeds are eaten fresh, roasted, or pressed to produce a milk-like extract (Takeuchi and Egea, 2020; Singhal et al., 2012; Santos et al., 2013; Keyvan et al., 2007). The commercialization of this nut provides one of the significant sources of income for many indigenous and riverine communities (Takeuchi and Egea, 2020; Singhal et al., 2012; Santos et al., 2013; Keyvan et al., 2007). The kernel is an excellent source of protein, energy, and minerals such as selenium (Se), calcium, and magnesium (Takeuchi and Egea, 2020). Selenium is the predominant mineral in Bertholletia excelsa essential in numerous physiological functions (Takeuchi and Egea, 2020). Bertholletia excelsa seed has a valuable bioactive composition, including phenolics, flavonoids, tocopherol, and phytosterols, unsaturated fatty acids, proteins, amino acids, and dietary fiber. Intake of phenolic compounds has been associated with potentially beneficial health effects 
related to anti-inflammatory, antimutagenic, and anticarcinogenic activities (Takeuchi and Egea, 2020).

The colossal trees reach up to $60 \mathrm{~m}$ in height and $16 \mathrm{~m}$ in circumference (Takeuchi and Egea, 2020). Although the name is Brazil Nuts, the most significant exporter of Brazil nuts is not Brazil, but Bolivia. In Brazil, these nuts are called castanhas-do-Para (Takeuchi and Egea, 2020; Singhal et al., 2012; Santos et al., 2013; Keyvan et al., 2007). It has a high concentration of lecithin, which contains choline (Takeuchi and Egea, 2020; Singhal et al., 2012; Keyvan et al., 2007). Choline is a building block for acethycholine (Singhal et al., 2012). These building blocks enhance the concentration of acethylcholine in Alzheimer's disease patients (Takeuchi and Egea, 2020; Singhal et al., 2012; Keyvan et al., 2007; Rusu et al., 2018).

\section{5) Moringa oleifera}

Moringa oleifera belongs to the family Moringaceae. The leaf extract of Moringa oleifera contains Vitamin $\mathrm{C}$ and $\mathrm{E}$ that are anti-oxidant and are involved in enhancing memory in Alzheimer's disease (Pakade et al., 2013; Mohan et al., 2005; Ganguly and Guha, 2008; Obulesu and Rao, 2011; Rao et al., 2012; Gulkari and Maske, 2020; Rajagopal et al., 2013).

\section{6) Ficus carica and Ficus benghalensis L. (Banyan)}

Ficus carica Linn. (Moraceae) commonly known as 'Anjir' (Hindi) is a small deciduous tree. The tree is cultivated in many parts of North-western and South India (Bhanushali et al., 2014). Phytochemical screening of the leaves has been characterized the presence of psoralen, bergapten, taraxasterol, $\beta$-sitosterol, lupeol, $\beta$-amyrin, coumarins, xanthotoxin, xanthotoxol, ficusin, tyrosin and marmesin (Bhanushali et al., 2014). The rural people use the fresh juice of the crushed plant to cure epilepsy and insanity (Bhanushali et al., 2014). The various parts of the plant are used by the rural people as a mild laxative, expectorant, antiinflammatory and diseases in liver and spleen as deobstruent (Bhanushali et al., 2014). Ficus carica as an antiepileptic drug. It also has sedative-hypnotic, skeletal muscle relaxant and anxiolytic actions on central nervous system (Bhanushali et al., 2014). This suggests that Ficus carica may be useful as therapeutic tool in insomnia, anxiety, schizophrenia, migraine and epilepsy (Bhanushali et al., 2014). It was also investigated for its effect in retrieval, retention and acquisition of spatial recognition (Bhanushali et al., 2014; Saxena et al., 2013; Gulkari and Maske, 2020; Rajagopal et al., 2013). Ficus carica contains quercetin that plays an important role in memory deficit and Alzheimer's disease due to its antioxidant activity (Bhanushali et al., 2014; Saxena et al., 2013; Gulkari and Maske, 2020; Rajagopal et al., 2013). Ficus carica at $200 \mathrm{mg} / \mathrm{kg}$ exhibited maximum nootropic response that is near to response exhibited by a standard drug Bacopa monniera (Bhanushali et al., 2014; Saxena et al., 2013; Gulkari and Maske, 2020; Rajagopal et al., 2013). In conclusion, Ficus carica at lower doses exhibits mild memory enhancing effet and higher doses evoke better learning ability and alter behavior (Bhanushali et al., 2014; Saxena et al., 2013; Gulkari and Maske, 2020; Rajagopal et al., 2013).

In traditional system of medicine, various plant parts of Ficus benghalensis L. (Banyan) such as stem bark, aerial roots, underground roots, vegetative buds, leaves, fruits and latex have been used in various nervous disorders i.e. seizure, insomnia, anxiety, etc. (Panday and Rauniar, 2016). Furthermore, orally administered aqueous extracts of aerial roots of Ficus benghalensis L. may have memory-enhancing, anxiolytic, musclerelaxant and seizure-modifying effect with no neurotoxic effect in Swiss albino mice (Panday and Rauniar, 2016).

\section{7) Nardostachys jatamansi}

Nardostachys jatamansi belongs to the family Caprifoliaceae (Valerianacae). Nardostachys jatamansi DC. is a small, perennial, dwarf, hairy, rhizomatous, herbaceous, endangered and the most primitive species in India, Nepal, Bhutan, Pakistan and himalayan region (Lyle et al., 2009; Rao et al., 2012). The species has very long history of use as medicine in Ayurveda. It contains sesquiterpene valeranone that has been used for the treatment of stress (Lyle et al., 2009; Rao et al., 2012). In Ayurveda, the roots of Nardostachys jatamansi have been clinically employed for their antiischemic, antioxidant, anticonvulsant, and neuroprotective activities. In a study, Nardostachys jatamansi exhibited memory retention and learning enhancing abilities in aged and young mice and reversed scopolamine and diazepam induced amnesia (Joshi and Parle, 2006; Rao et al., 2012). Nardostachys jatamansi also reversed aging induced amnesia (Joshi and Parle, 2006). As scopolamine-induced amnesia was reversed, it is possible that the memory improvement may be because of facilitation of cholinergic 
transmission in the brain (Joshi and Parle, 2006; Rao et al., 2012). Hence, Nardostachys jatamansi might prove to be a useful memory restorative agent in the treatment of dementia seen in elderly persons (Joshi and Parle, 2006). Karkada et al., (2012) reported efficacy of Nardostachys jatamansi in the prevention of stress induced memory deficit. Cognitive enhancers can help keep ones brain working properly. Mental awareness, concentration, quickness, intelligence and more can all be improved by the use of these medications (Joshi and Parle, 2006; Rao et al., 2012).

\section{8) Clitoria ternatea (L.) (Butterfly pea) (Shankpushpi)}

Clitoria ternatea (L.) belongs to the family Leguminosae commonly known as Shankpushpi, the butterfly pea, blue or white pea, aparajita is a perennial ornamental twinning herb conspicuous for its large papilionaceous corolla (Malabadi, 2002, 2003; Malabadi and Nataraja, 2001, 2002a, 2002b, 2004; Malabadi et al., 2005, 2007). Clitoria ternatea may also be the memory booster or enhancer in any disorders related to loss of learning ability and disorders of memory as in Alzheimer's disease (Malabadi et al., 2005, 2007; Kosai et al., 2015; Taranahalli and Cheeramkuzh, 2000; Rai et al., 2002; Jain et al., 2003; Sarwar et al., 2014; Rai et al., 2001). Clitoria ternatea is widely used in the traditional Indian system of medicine as a brain tonic and is believed to promote memory and intelligence. Clitoria ternatea (L.) is reported to be a good brain tonic mainly used in the treatment of mental illness. The plant has thus been evaluated extensively for various pharmacological activities (Malabadi et al., 2005, 2007; Kosai et al., 2015; Taranahalli and Cheeramkuzh, 2000; Rai et al., 2002; Jain et al., 2003; Sarwar et al., 2014; Rai et al., 2001). This genus has 70 species of which three are from India (Malabadi, 2002, 2003; Malabadi and Nataraja, 2001, 2002a, 2002b, 2004; Malabadi et al., 2005, 2007). The plant is considered to be a good brain tonic and is useful for throat, eye infections, skin diseases, urinary troubles, an ulcer, antidotal, in improving memory and intelligence. The root has a sharp bitter taste with antihelmintic, analgesic, antipyretic, and anti-inflammatory properties (Malabadi, 2002, 2003; Malabadi and Nataraja, 2001, 2002a, 2002b, 2004; Malabadi et al., 2005, 2007). The plant is used for curing severe bronchitis, asthma, hectic fever and also as a tonic against ulcers of the cornea and tuberculoses. Roots are emetic and are used by the local tribes to cause abortion. Root paste is applied on the stomach of cattle for urinary and abdominal swellings, sore throat, mucous disorders and fever (Malabadi, 2002, 2003; Malabadi and Nataraja, 2001, 2002a, 2002b, 2004; Malabadi et al., 2005, 2007).

The effectiveness of alcoholic extracts of aerial and root parts of Clitoria ternatea at 300 and $500 \mathrm{mg} / \mathrm{kg}$ doses orally in rats in attenuating electroshock-induced amnesia was studied and recorded (Kosai et al., 2015; Taranahalli and Cheeramkuzh, 2000; Rai et al., 2002; Jain et al., 2003; Sarwar et al., 2014; Rai et al., 2001). Extracts at $300 \mathrm{mg} / \mathrm{kg}$ dose produced significant memory retention, and the root parts were found to be more effective. Therefore, this study demonstrated the influence on central cholinergic activity by estimating the acetylcholine content of the whole brain and acetylcholinesterase activity at different regions of the rat brain, viz., cerebral cortex, midbrain, medulla oblongata and cerebellum (Kosai et al., 2015; Taranahalli and Cheeramkuzh, 2000; Rai et al., 2002; Jain et al., 2003; Sarwar et al., 2014; Rai et al., 2001). Experimental results confirmed that Clitoria ternatea extracts increase rat brain acetylcholine content and acetyl cholinesterase activity in a similar fashion to the standard cerebro protective drug pyritinol (Kosai et al., 2015; Taranahalli and Cheeramkuzh, 2000; Rai et al., 2002; Jain et al., 2003; Sarwar et al., 2014; Rai et al., 2001).

\section{Other medicinal plants used in the treatment of Alzheimer's disease}

Herbal therapy can improve the life quality of patients with Alzheimer's disease and memory deficits. Herbs may play a promising role in the early treatment of Alzheimer's and other conditions involving poor memory and dementia. One of the chief benefits is that they have a low toxicity compared to pharmaceutical agents. Medicinal plants effective in the treatment of Alzheimer's disease are 39) Golden Rose / Golden Root (Rhodiola rosea) (Mattioli and Perfumi, 2011), 40) St John's Wort (Hypericum perforatum) (Ellis et al., 2001), 41) Lycopodium saururus (Huperzia saururus) (Ortega et al., 2006), 42) Sesame (Sesamum indicum) (Um et al., 2009), 43) Green Tea (Camellia sinensis) (Chang et al., 2016), 44) Coconut Milk Powder (Cocos nucifera) (Rajagopal et al., 2013; Gulkari and Maske, 2020; Singhal, 2012; Tabassum et al., 2012). 45) Celastrus paniculatus (Celastraceae) (Rajagopal et al., 2013), 46) Pinus maritima (Pinaceae) (Rajagopal et al., 2013), 47) Polygala tenuifolia (Polygalaceae) 
(Rajagopal et al., 2013), 48) Polygonum multiflorum (Polygonaceae) (Rajagopal et al., 2013), 49) Salix alba (Rajagopal et al., 2013), 50) Uncaria rhynchophylla (Rubiaceae) (Rajagopal et al., 2013), 51) Siberian Ginseng (Eleutherococcus sentiocosus) (Rajagopal et al., 2013), 52) and Urtica galeopsifolia (Clusiaceae) (Rajagopal et al., 2013), and 53) Cloves (Lavang in Kannada) (Syzygium aromaticum) (Milind and Deepa, 2011).

Multiple herbs are often combined in complex formulations in some traditional medical systems for the treatment of various diseases (Chang et al., 2016). Evidence to support these beneficial interactions is very limited and results remain controversial (Chang et al., 2016). The current clinical evidence to support the use of complex herbal formulations for dementia and/or Alzheimer's disease remains weak and controversial (Chang et al., 2016).

\section{Conclusion}

Medicinal plants have demonstrated potential therapeutic benefits for improving cognitive function in Alzheimer's patients. Herbal medicines enhance the brain's ability to function, and therefore, provide stability when used consistently. However, much of the evidence comes from animal and in vitro studies and overall clinical Evidence-Based Complementary and Alternative Medicine evidence to support these herbal interventions remains weak and lacking. In addition to this, there are many experimental issues and data presented is not enough for the scientific validation. The treatment durations in the existing trials are also of concern. Dementia is a progressive disease and therefore longer duration clinical trials are required to appropriately assess the effects of interventions on the disease progress. The current evidence to support their use alone, however, is inconclusive or inadequate. This uncertainty is mainly caused by methodological limitations such as poor study design, relatively small sample sizes without a power calculation, inappropriate outcome measures and primary and secondary end-point selection, and invalid statistical analysis. Future epidemiological and clinical studies are required to further assess the benefits of herbal medicines for the prevention of dementia and/or Alzheimer's disease. Therefore, the scientific evidence is generally lacking and further research is needed to assess synergism of herbal medicine. The use of herbal medicine in the treatment of human health disorders is promising but requires further development in terms of large scale clinical trials. The literature survey reported in this updated review paper demonstrated the feasibility and potential of developing evidence-based herbal medicines for the treatment of Alzheimer's disease. The use of herbal medicines in the treatment of Alzheimer's disease should be compared with the pharmacological treatment currently in use. Such studies should include identification of the active principle in order to improve the validation of the clinical trial. Further large-scale, multicenter studies are necessary to determine the effectiveness of these substances in the cognitive deterioration of Alzheimer's disease. Herbal medicines are fundamentally preventive, protective, nutritive and curative. Herbal medicines are less expensive and are more effective than allopathic medicines without any side effects.

\section{Conflict of interest statement}

Authors declare that they have no conflict of interest.

\section{References}

Abe, K., Saito, H., 2000. Effects of saffon and its constituent crocin on learning behavior and longterm potentiation. Phytother. Res., 14: 149-152.

Agarwal, A., Malini, S., Bairy, K. L., Rao, M. S., 2002. Effect of Tinospora cordifolia on learning and memory in normal and memory deficit rats. Indian J. Pharmacol., 34: 339-349.

Aguiar, S., Borowski, T., 2013. Neuropharmacological review of the nootropic herb Bacopa monnieri. Rejuven. Res., 16(4): 313-326.

Akhondzadeh, S., Noroozian, M., Mohammadi, M., Ohadinia, S., Jamshidi, A. H., Khani, M., 2003. Salvia officinalis extract in the treatment of patients with mild to moderate Alzheimer's disease: a double blind, randomized and placebo-controlled trial. J. Clin. Pharm. Ther. 28: 53-59.

Akhondzadeh, S., Sabet, M. S., Harirchian, M. H., et al., 2010a. A 22-week, multicenter, randomized, double-blind controlled trial of Crocus sativus in the treatment of mild-to-moderate Alzheimer's disease. Psychopharmacol., 207(4): 637-643.

Akhondzadeh, S., Sabet, M. S., Harirchian, M. H., et al., 2010b. Saffron in the treatment of patients with mild to moderate Alzheimer's disease: a 16-week, randomized and placebo-controlled trial. J. Clin. Pharm. Therapeut., 35(5): 581-588.

Akram, M., Nawaz, A., 2017. Effects of medicinal 
plants on Alzheimer's disease and memory deficits. Neural Regenerat. Res., 12(4): 660-670.

Al-Sereiti, M. R., Abu-Amer, K. M., Sen, P., 1999. Pharmacology of rosemary (Rosmarinus officinalis Linn.) and its therapeutic potentials. Indian J. Exp. Biol., 37: 124-130.

Asgarpanah, J., Kazemivash, N., 2012. Phytochemistry and pharmacologic properties of Myristica fragrans Hoyutt.: A review. Afr. J. Biotechnol., 11: 1278712793.

Asuthosh, S., Malini, K., Bairy, M., 2000. Effect of Tinospora cordifolia on learning and memory in normal and memory deficits rats. Indian $\mathrm{J}$. Pharmacol., 34: 339-349.

Bai, D. L., Tang, X. C., He, X. C., 2000. Huperzine A, a potential therapeutic agent for treatment of Alzheimer's disease. Curr. Med. Chem., 7: 355374.

Balakumbahan, R., Rajamani, K., Kumanan, K., 2010. Acorus calamus: An overview. J. Med. Plant Res., 4: 2740-2745.

Bastos, D., Oliveira, D., Matsumoto, R., Carvalo, P., Ribeiro, M., 2007. Yerba mate (Ilex paraguariensis): pharmacological research, research and biotechnology. Med. Plant Aromat. Plant Sci. Biotechnol., 1: 37-46.

Bhanumathy, M, Harish, M. S., Shivaprasad, H. N., Sushma, G., 2010. Nootropic activity of Celastrus paniculatus seed. Pharm Biol., 48: 324-327.

Bhanushali, M. M., Makhija, D. T., Joshi, Y. M., 2014. Central nervous system activity of an aqueous acetonic extract of Ficus carica L. in mice. J. Ayurveda Integr. Med., 5(2): 89-96.

Bhatnagar, M., Sharma, D., Salvi, M., 2009. Neuroprotective effects of Withania somnifera Dunal.: A possible mechanism. Neurochem. Res., 34: 1975-1983.

Bickel, U., Thomsen, T., Weber, W., Fischer, J. P., Bachus, R., Nitz, M., Kewitz, H., 1991. Pharmacokinetics of galanthamine in human and corresponding cholinesterase inhibition. Clin. Pharmacol. Therapeut. 50: 420-428.

Bihaqi, S. W., Singh, A. P., Tiwari, M., 2011. In vivo investigation of the neuroprotective property of Convolvulus pluricaulis in scopolamine induced cognitive impairments in Wistar rats. Indian $\mathrm{J}$. Pharmacol., 43: 520-525.

Borges, R. S., Ortiz, B. L. S., Pereira, A. C. M., Keita, H., Carvalho, J. C. T., 2019. Rosmarinus officinalis essential oil: A review of its phytochemistry, antiinflammatory activity, and mechanisms of action involved. J. Ethnopharmacol., 229: 29-45.

Braidy, N., Matin, A., Rossi, F., Chinain, M., Laurent, D., Guillemin, G. J., 2014. Neuroprotective effects of rosmarinic acid on ciguatoxin in primary human neurons. Neurotox. Res., 25: 226-234.

Brinkhaus, B., Lindner, M., Schuppan, D., Hahn, E. G., 2000. Chemical, pharmacological and clinical profile of the East Asian medical plant Centella asiatica. Phytomedicine, 7: 427-448.

Bubeva-Ivanova, L., 1957. Phytochemical study on Galanthus nivalis var. gracilis. Pharmacia, 2: 23-26 (in Bulgarian).

Chakravarthi, K. K., Avadhani, R., 2013. Beneficial effect of aqueous root extract of Glycyrrhiza glabra on learning and memory using different behavioral models: An experimental study. J. Nat. Sci. Biol. Med., 4(2): 420-425.

Chang, D., Liu, J., Bilinski, K., Xu, L., Steiner, G. Z., Seto, S.S., Bensoussan, A., 2016. Herbal medicine for the treatment of vascular dementia: An overview of scientific evidence. Evid. Based Complement. Alternat. Med., 2016: 5223013.

Chen, Y. L., Lin, K. F., Shiao, M. S., Chen, Y. T., Hong, C. Y., Lin, S. J., 2001. Magnolol, a potent antioxidant from Magnolia officinalis, attenuates intimal thickening and MCP-1 expression after balloon injury of the aorta in cholesterol fed rabbits. Basic Res. Cardiol., 96: 353-363.

Choi, R. C. Y., Zhu, J. T. T., Leung, K. W., et al., 2010. A flavonol glycoside, isolated from roots of Panax notoginseng, reduces amyloid-induced neuro toxicity in cultured neurons: signaling transduction and drug development for Alzheimer's disease. J. Alzheimer's Dis., 19(3): 795-811.

Chu, S., Gu, J., Feng, L., et al., 2014. Ginsenoside Rg5 improves cognitive dysfunction and beta-amyloid deposition in STZ induced memory impaired rats via attenuating neuro-inflammatory responses. Int. Immunopharmacol., 9(2): 317-326.

Chuang, C. M., Hsieh, C. L., Lin, H. Y., Lin, J. G., 2008. Panax notoginseng Burk attenuates impairment of learning and memory functions and increases ED1, BDNF and -secretase immunoreactive cells in chronic stage ischemiareperfusion injured rats. Amer. J. Chinese Med., 36(4): 685-693.

Colpo, G., Trevisol, F., Teixeira, A., Fachinetto, R., Pereira, R., Rocha, B., 2007. Ilex paraguariensis has antioxidant potential and attenuates haloperidolinduced orofacial dyskinesia and memory dysfunction in rats. Neurotox. Res., 12: 171-180. 
Cummings, J., Lee, G., Ritter, A., Sabbagh, M., Zhong, K., 2020. Alzheimer's disease drug development pipeline. Alzheimer's Dement., 6: e12050. (https://doi.org/10.1002/trc2.12050).

Dal-Bianco, P., Maly, J., Wober, C., Lind, C., Koch, G., Hufgard, J., Marschall, I., Mraz, M., Deecke, L., 1991. Galanthamine treatment in Alzheimer's disease. J. Neural Trans. (Suppl. 133): 59-63.

Das, M., Mallavarapu, G. R., Kumar, S., 1998. Chamomile (Chamomilla recutita): Economic botany, biology, chemistry, domestication and cultivation. J. Med. Aromat. Plant Sci., 20: 10741109.

De-Oliveira, J. R., Camargo, S. E. A., de Oliveira, L. D., 2019. Rosmarinus officinalis L. (rosemary) as therapeutic and prophylactic agent. J. Biomed. Sci., 26: 5 .

Dhanasekaran, M., Tharakan, B., Holcomb, L. A., Hitt, A. R., Young, K. A., Manyam, B. V., 2007. Neuroprotective mechanisms of ayurvedic antidementia botanical Bacopa monniera. Phytother. Res., 21: 965-969.

Dhingra, D., Parle, M., Kulkarni, S. K., 2004. Memory enhancing activity of Glycyrrhiza glabra in mice. J. Ethnopharmacol., 91(2-3): 361-365.

Dubey, G. P., Pathak, S. R., Gupta, B.S., 1994. Combined effect of brahmi (Bacopa monniera) and shankhpushpi (Convolvulus pluricaulis) on cognitive functions. Pharmacopsychoecol., 7: 249251.

Eidi, M., Eidi, A., Bahar, M., 2006. Effects of Salvia officinalis L. (sage) leaves on memory retention and its interaction with the cholinergic system in rats. Nutrition., 22: 321-326.

Ellis, K. A., Stough, C., Vitetta, L., Heinrich, K., Nathan, P. J., 2001. An investigation into the acute nootropic effects of Hypericum perforatum L. (St. John's Wort) in healthy human volunteers. Behav. Pharmacol., 12: 173-182.

Erkinjunti, T., Kurz, A., Gauthier, S., Bullock, R., Lilienfeld, S., Venkata Damaraju, C. R., 2002. Efficacy of galantamine in probable vascular dementia and Alzheimer's disease combined with cerebrovascular disease: a randomised trial. Lancet., 359: 1283-1290.

Esfandiari, E., Ghanadian, M., Rashidi, B., Mokhtarian, A., Vatankhah, A. M., 2018. The Effects of Acorus calamus L. in preventing memory loss, anxiety, and oxidative stress on lipopolysaccharide-induced neuro-inflammation rat models. Int. J. Prev. Med. 9: 85.
Evans, D. A., Funkenstein, H. H., Albert, M. S., 1989. Prevalence of Alzheimer's disease in a community population of older persons: Higher than previously reported. J. Amer. Med. Assoc., 262: 2551-2556.

Farokhnia, M., Shafiee, S. M., Iranpour, N., Gougol, A., Yekehtaz, H., Alimardani, R., Fasrad, F., Kamalipour, M., Akhondzadeh, S., 2014. Comparing the efficacy and safety of Crocus sativus with memantine in patient with moderate to severe Alzheimer's disease: a double blind randomized clinical trial. Hum. Psychopharmacol. 29: 351-359.

Farlow, M. R., 2001. Pharmacokinetics profiles of current therapies for AD: implications for Switching to galanthamine. Clin. Therapeut. 23: A13-A24.

Faiyaz, A., Narendra, J., Sharath, C., 2011. Acetylcholine and memory-enhancing activity of Ficus racemosa bark. Pharmacog. Res. 3: 246-249.

Fulton, B., Benfield, P., 1996. Galanthamine. Drugs and Aging, 9: 60-65.

Ganachari, M. S., Babu, V., Katare, S., 2004. Neuropharmacology of an extract derived from Centella asiatica. Pharm. Biol., 42: 246-252.

Ganguly, R., Guha, D., 2008. Alteration of brain monoamines \& EEG wave pattern in rat model of Alzheimer's disease and protection by Moringa oleifera. Indian J. Med. Res., 128: 744-751.

Gharibi, A., Khalili, M., Kiasalari, Z., Hoseinirad, M., 2013. The effect of Zingiber officinalis L. on learning and memory in rats. J. Basic Clin. Pathophysiol., 2: 2013-2014.

Ghorbani, A., Esmaeilizadeh, M., 2013. Pharmacological properties of Salvia officinalis and its components. Postepy Dermatol. Alergol., 30(1): 46-49.

Godkar, P., Gordon, R., Ravindran, A., 2003. Celastrus paniculatus seed water soluble extracts protect cultured rat forebrain neuronal cells from hydrogen peroxide-induced oxidative injury. Fitoterapia, 74: 658-669.

Gohil, K. J., Patel, J. A., Gajjar, A. K., 2010. Pharmacological review on Centella asiatica: A potential herbal cure-all. Indian J. Pharm. Sci., 72(5): 546-556.

Gujran, S., Singh, S. P., Pal, R., Singh, S., Ram, P., Nath, C., 2007. Gugulipid, an extract of Commiphora whighitti with lipid lowering properties, has protective effects against streptozotocin induced memory deficits in mice. Pharmacol. Biochem. Behav., 8: 797-805.

Gulkari, V. D., Maske, D. K., 2020. Role of herbal 
drugs in the preventation and treatment of Alzheimer's disease. World J. Pharmaceut. Res., 9(7): 1042-1074.

Heck, C. I., De Mejia, E. G., 2007. Yerba Matic tea (Ilex paraguariensis), A comprehensive review on chemistry. Health complications and technological considerations. J. Food Sci., 72: 138-151.

Jae, L., Kyung, L., Beom, J., Yoon, N., Sang, L., Hong, T., 2009. Inhibitory effect of ethanol extract of Magnolia officinalis and 4-O-methylhonokiol on memory impairment and neuronal toxicity induced by beta-amyloid. Pharmacol. Biochem. Behav. 95: 31-40.

Hanumanthacar, J., Milind, P., 2006. Zingiber officinale: Evaluation of its nootropic effect in mice. Afr. J. Trad. Complement. Alternat. Med., 3: 64-74.

Haque, N., Sofi, G., Ali, W., Rashid, M., Itrat, M. A., 2015. Comprehensive review of phytochemical and pharmacological profile of Anar (Punica granatum Linn): A heaven's fruit. J. Ayu. Herb. Med., 1(1): 22-26.

Hardy, J., Selkoe, D. J., 2002. The amyloid hypothesis of Alzheimer's disease: Progress and problems on the road to therapeutics. Science, 297: 353-356.

Harvey, A. L., 1995. The pharmacology of galanthamine and its analogues. Pharmacol. Therapeut., 68: 113-128.

Heinrich, M., Teoh, H. L., 2004. Galanthamine from snowdrop - the development of a modern drug against Alzheimer's disease from local Caucasian knowledge. J. Ethnopharmacol., 92: 147-162.

Heneka, M. T., O'Banion, M. K., 2007. Inflammatory processes in Alzheimer's disease. J. Neuroimmunol., 184: 69-91.

Hou, Y. C., Chao, P. D., Chen, Y. T., 2000. Honokiol and magnolol increased hippocampal acetylcholine release in freely moving rats. Am. J. Chin. Med., 28: 379-384.

Howes, J., Houghton, J., 2012. Ethnobotanical treatment strategies against Alzheimer's disease. Curr. Alzheimer Res., 9: 67-85.

Jain, N. N., Ohal, C. C., Shroff, S. K., Bhutada, R. H., Somani, R. S., Kasture, V. S., Kasture, S.B., 2003. Clitoria ternatea and the CNS. Pharmacol. Biochem. Behav., 75(3): 529-536.

Jaswinder, K., Rajmeet, S., Gurinder, S., Harpreet, K., Jasvir, K., Manpreet, K., Parminder, S., Jaspreet, K., 2016. A systematic review on Huperzia serrata. Int. J. Pharmac. Phytochem. Res., 8(8): 1250-1255.

Jie, M., Hu, Y., Hang, H., 2000. Study on anti-oxidant effect of Magnolia officinalis. Zhongguo Youzhi.
25: 30-32.

Joshi, H., Parle, M., 2006. Nardostachys jatamansi improves learning and memory in mice. J. Med. Food. 9: 113-118.

Julio, R., Dang, H., Gong, M., Gonzales, F., 2007. Aqueous and hydroalcoholic extracts of black maca (Lepidium meyenii) improve scopolamine-induced memory impairment in mice. Food Chem. Toxicol. 45: $1882-1890$.

Jun, L., 2008. Huperzine A for Alzheimer's disease (review). Cochrane Database Systemat. Rev., 2: 3646.

Jureneka, J. M. T., 2008. Therapeutic application of pomegranate (Punica granatum Linn). Alternat. Med. Rev., 13: 128-144.

Karkada, G., Shenoy, K., Halahalli, H., Karanth, K., 2012. Nardostachys jatamansi extract prevents chronic restraint stress-induced learning and memory deficits in a radial arm maze task. J. Nat. Sci. Biol. Med., 3: 125-132.

Katekhaye, S., Duggal, S., Singh, A., 2011. An inside preview of nutritional and pharmacological profile of Celastrus paniculatus. Int. J. Recent Adv. Pharm. Res., 1: 19-24.

Katzman, R., 1976. The prevalence and malignancy of Alzheimer's disease. A major killer. Arch. Neurol., 33: 217-218.

Kaushik, R., Morkovin, E., Schneeberg, J., et al., 2018. Traditional Japanese herbal medicine Yokukansan targets distinct but overlapping mechanisms in aged mice and in the 5xFAD mouse model of Alzheimer's disease. Front. Aging Neurosci., 10: 411.

Kayashima, T., Matsubara, K., 2012. Antiangiogenic effect of carnosic acid and carnosol, neuroprotective compounds in rosemary leaves. Biosci. Biotechnol. Biochem., 76: 115-119.

Kennedy, D. O., Pace, S., Haskell, C., Okello, E. J., Milne, A., Scholey, A. B., 2006. Effects of cholinesterase inhibiting sage (Salvia officinalis) on mood, anxiety and performance on a psychological stressor battery. Neuropsychopharmacology, 31: 845-852.

Kewitz, H., 1997. Pharmacokinetics and metabolism of galanthamine. Drugs of Today, 33: 265-272.

Keyvan, D., Damien, D. H. J., Heikki, V., Raimo, H., 2007. Plants as potential sources for drug development against Alzheimer's disease. Int. J. Biomed. Pharm. Sci., 1: 83-104.

Khondzadeh, S. A., Abhasi, S. H., 2006. Herbal medicine in the treatment of Alzheimer's disease. 
Amer. J. Alzheimer's Dis. Other Dementias, 21(2): 113-118.

Kong, C. W., Tsai, K., Chin, J. H., Chan, W. L., Hong, C. Y., 2000. Magnolol attenuates per oxidative damage and improves survival of rats with sepsis. Shock., 12: 24-28.

Kosai, P., Sirisidthi, K., Jiraungkoorskul, K., Jiraungkoorskul, W., 2015. Review on ethnomedicinal uses of memory boosting herb, butterfly pea, Clitoria ternatea. J. Natural Remed., 15(2): 71-76.

Kregiel, D., Pawlikowska, E., Antolak, H., 2018. Urtica spp.: Ordinary plants with extraordinary properties. Molecules, 23: 1664.

Kumar, M. H., Gupta, Y. K., 2002. Antioxidant property of Celastrus paniculatus Willd.: A possible mechanism in enhancing cognition. Phytomedicine, 9: 302-211.

Kumar, V., Dey, A., Hadimani, M. B., Marcović, T., Emerald, M., 2015. Chemistry and pharmacology of Withania somnifera: An update. TANG / www.etang.org. 5(1): 1-13.

Kulkarni, S. K., Dhir, A., 2008. Withania somnifera: An Indian ginseng. Prog. Neuropsychopharmacol. Biol. Psychiat., 32: 1093-1105.

Kumar, D. V., Geethanjali, B., Avinash, K. O., Kumar, J. R., Chandrashekrappa, G. K., Basalingappa, K. M., 2017. Tinospora cordifolia: the antimicrobial property of the leaves of Amruthaballi. J. Bacteriol. Mycol., 5: 363-371.

Lahiri, D. K., Farlow, M. R., Greig, N. H., Sambamurti, K., 2002. Current drug targets for Alzheimer's disease treatment. Drug Develop. Res., 56: 267281.

Lannert, H., Hoyer, S., 1998. Intracerebroventricular administration of streptozotocin causes long-term diminutions in learning and memory abilities and in cerebral energy metabolism in adult rats. Behav. Neurosci., 112: 1199-1208.

Lee, J., Jin, C., Cho, S. Y., Park, S. U., Jung, W. S., Moon, S. K., Park, J. M., Ko, C. N., Cho, K. H., Kwon, S., 2020. Herbal medicine treatment for Alzheimer's disease: A protocol for a systematic review and meta-analysis. Medicine, 99: 33 (e21745).

Lee, Y., Yuk, D., Kim, T., Nam, S., Hong, J., 2009. Protective effect of the ethanol extract of Magnolia officinalis and 4-O-methylhonokiol on scopolamine -induced memory impairment and the inhibition of acetylcholinesterase activity. J. Nat. Med., 63: 274282.
Lim, H. S., Kim, Y. J., Sohn, E., et al., 2018. Bojungikgi-Tang, a traditional herbal formula, exerts neuroprotective effects and ameliorates memory impairments in Alzheimer's disease-like experimental models. Nutrients, 10: 1952.

Liou, K. T., Shen, Y. C., Chen, C. F., Taso, C. M., Tsai, S. K., 2003. The anti-inflammatory effect of honokiol on neutriprils: mechanism in the inhibition of reactive oxygen species production. Eur. J. Pharmacol., 47: 19-27.

Li, Q., Weng, X., 2005. Antioxidant activity of Magnolia officinalis. Zhongguo Youzhi, 30: 37-40.

Liu, J. S., Yu, C. M., Zhou, Y. Z., Han, Y. Y., Wu, F. W., Qi, B. F., Zhu, Y. L., 1986. Study on the chemistry of huperzine-A and huperzine-B. Acta Chim. Sin., 44: 1035-1040.

Liu, J., Chang, D., 2006. Vascular dementia. J. Complement. Med., 5: 14-20.

Lyle, N., Bhattacharyya, D., Sur, T., Munshi, S., Paul, S., Chatterjee, S., Gomes, A., 2009. Stress modulating antioxidant effect of Nardostachys jatamansi. Indian J. Biochem. Biophys., 46: 93-98.

Lyte, M., 2011. Probiotics function mechanistically as delivery vehicles for neuroactive compounds: Microbial endocrinology in the design and use of probiotics. Bioessays, 33: 74-81.

Maeda, A., Tanimoto, S., Abe, T., Kazama, S., Tanizawa, H., Nomura, M., 2008. Chemical constituents of Myristica fragrans Houttuyn seed and their physiological activities. Yakugaku Zasshi, 128: 129-133.

Malabadi, R. B., Nataraja, K., 2001. Shoot regeneration in leaf explants of Clitoria ternatea $\mathrm{L}$. cultured in vitro. Phytomorphology, 51(2): 169-171.

Malabadi, R. B., 2002. Histological changes associated with shoot regeneration in the leaf explants of Clitoria ternatea (Linn.) cultured in vitro. J. Phytol. Res., 15(2): 169-172.

Malabadi, R. B., Nataraja, K., 2002a. In vitro storage of synthetic seeds in Clitoria ternatea (Linn.). Phytomorphology, 52(2\&3): 231-237.

Malabadi, R. B., Nataraja, K., 2002b. In vitro plant regeneration in Clitoria ternatea. J. Med. Arom. Plant Sci., 24: 733-737.

Malabadi, R. B., 2003. Protoplast isolation, culture and plant regeneration in butterfly pea (Clitoria ternatea Linn.). Indian J. Genet. Plant Breed., 63(3): 243246.

Malabadi, R. B., Nataraja, K., 2004. Cryopreservation and plant regeneration via somatic embryogenesis in Clitoria ternatea. Phytomorphology, 54: 7-17. 
Malabadi, R. B., Mulgund, G. S., Nataraja, K., 2005. Screening of antibacterial activity in the extracts of Clitoria ternatea (Linn.). J. Med. Arom. Plant Sci., 27: 26-29.

Malabadi, R. B., Mulgund, G. S., Nataraja, K., 2007. Ethanobotanical survey of medicinal plants of Belgaum district, Karnataka, India. J. Med. Arom. Plant Sci., 29(2): 70-77.

Malabadi, R. B., 2008. Production of edible vaccines for oral immunization in transgenic plants, current and future prospective. J. Phytol. Res., 21(1): 1-10.

Malabadi, R. B., Vijay Kumar, S., 2008. Evaluation of antifungal property of medicinal plants. J. Phytol. Res., 21(1): 139-142.

Malabadi, R. B., Mulgund, G. S., Nataraja, K., 2009. Triacontanol induced somatic embryogenesis and plantlet regeneration in Catharanthus roseus. J. Med. Arom. Plant Sci., 31: 147-151.

Malabadi, R. B., Mulgund, G. S., Nataraja, K, 2010 a. Evaluation of antifungal activity of selected medicinal plants. J. Med. Arom. Plant Sci., 32(1): 42-45.

Malabadi, R. B., Parashar, A., Ganguly, A., Suresh, M. R., 2010b. Expression of dengue virus envelope protein in a different plant system. Faculty Research and Development day, Faculty of Pharmacy and Pharmaceutical Sciences, University of Alberta, Edmonton, Canada, 19th November 2010. Abstract No-69, page no. 31.

Malabadi, R. B., Ganguly, A., Teixeira da Silva, J. A., Parashar, A., Suresh, M. R., Sunwoo, H. H., 2011. Overview of plant-derived vaccine antigens: dengue virus. J. Pharm. Pharm. Sci., 14: 400-413.

Malabadi, R. B., Vijayakumar, S., Mulgund, G. S., Nataraja, K., 2011. Induction of somatic embryogenesis in papaya (Carica papaya). Res. Biotechnol., 2(5): 40-55.

Malabadi, R. B., Chalannavar, R. K., Meti, N. T., Mulgund, G. S., Nataraja, K., Vijayakumar, S., 2012a. Synthesis of antimicrobial silver nanoparticles by callus cultures and in vitro derived plants of Catharanthus roseus. Res. Pharm., 2(6): 18-31.

Malabadi, R. B., Meti, N. T., Mulgund, G. S., Nataraja, K., Vijayakumar, S., 2012b. Synthesis of silver nanoparticles from in vitro derived plants and callus cultures of Costus speciosus (Koen.): Assessment of antibacterial activity. Res. Plant Biol., 2(4): 32-42.

Malabadi, R. B., Mulgund, G. S., Meti, N. T., Nataraja, K., Vijayakumar, S., 2012c. Antibacterial activity of silver nanoparticles synthesized by using whole plant extracts of Clitoria ternatea. Res. Pharm., 2(4): 10-21.

Malabadi, R. B., Lokare-Naik, S., Meti, N. T., Mulgund, G. S., Nataraja, K., Vijayakumar, S., 2012d. Synthesis of silver nanoparticles from in vitro derived plants and callus cultures of Clitoria ternatea: Evaluation of antimicrobial activity. Res. Biotechnol., 3(5): 26-38.

Malabadi, R. B., Chalannavar, R. K., Sowmyashree, K., Supriya, S., Nityasree, B. R., Gleiser, R. M., Meti, N. T., Vijayakumar, S., Mulgund, G. S., Gani, R. S., Nasalapure, A., Chougale, R., Masti, S., Chougale, A., Divakar, M. S., Kasai, D., Odhav, B., Baijnath, H., 2016a. Ebola virus: Updates on plant made vaccine development. Int. J. Res. Scient. Innov., 3(6): 4-12.

Malabadi, R. B., Chalannavar, R. K., Meti, N. T., Vijayakumar, S., Mulgund, G. S., 2016b. Plant viral expression vectors and agroinfilteration: A literature review update. Int. J. Res. Scient. Innov., 3(IV): 3236.

Malabadi, R. B., Chalannavar, R. K., Meti, N. T., Gani, R. S., Vijayakumar, S., Mulgund, G. S., Masti, S., Chougale, R., Odhav, B., Sowmyashree, K., Supriya, S., Nityasree, B. R., Divakar, M. S., 2016c. Insulin plant, Costus speciosus: Ethnobotany and pharmacological updates. Int. J. Curr. Res. Biosci. Plant Biol. 3(7): 151-161.

Malabadi, R. B., Chalannavar, R. K., Meti, N. T., Vijayakumar, S., Mulgund, G. S., Gani, R. S., Supriya, S., Sowmyashree, K., Nityasree, B. R., Chougale, A., Divakar, M. S., 2016d. Antidiabetic plant, Gymnema sylvestre R. Br., (Madhunashini): Ethnobotany, phytochemistry and pharmacological updates. Int. Curr. Trends Pharmacobiol. Med. Sci., 1(4): 1-17.

Malabadi, R. B., Chalannavar, R. K., Supriya, S., Nityasree, B. R., Sowmyashree, K., Gangadhar, S., Mulgund, G. S., Meti, N. T., 2017a. Dengue virus disease: Recent updates on vaccine development. Int. J. Res. Scient. Innov., 4(7): 8-29.

Malabadi, R. B., Chalannavar, R. K., Supriya, S., Nityasree, B. R., Sowmyashree, K., Gangadhar, S., Mulgund, G. S., Meti, N. T., 2017b. Dengue virus disease: Current updates on the use of Carica papaya leaf extract as a potential herbal medicine. Int. J. Res. Scient. Innov., 4(8): 36-50.

Malik, J., Karan, M., Vashist, K., 2011. Nootropic, anixolytic and CNS depressant studies on different plant sources of shankhpushpi. Pharm. Biol. 49: 1234-1242. 
Malhotra, S., Singh, A. P., 2003. Medicinal properties of ginger (Zingiber officinale Rosc.). Nat. Prod. Rad., 2: 296-301.

Mani, V., Milind, P., 2007. Memory enhancing activity of Emblica officinalis Gaertn: An ayurvedic preparation. Physiol. Behav., 91: 46-54.

Malve, H., Raut, S., Marathe, P., Rege, N., 2014. Effect of combination of Phyllanthus emblica, Tinospora cordifolia and Ocimum sanctum on spatial learning and memory in rats. J. Ayurv. Integr. Med., 5: 209215.

Masuda, T., Jitoe, A., Takeda, Y., 1997. Synthesis of cassumunin A, a potent anti-inflammatory, antioxidant from a medicinal ginger. Nat. Prod. Lett., 39: 342-348.

Mattioli, L., Perfumi, M., 2011. Effects of a Rhodiola rosea $\mathrm{L}$. extract on acquisition and expression of morphine tolerance and dependence in mice. $\mathrm{J}$. Psychopharmacol., 25: 411-420.

May, B. H,, Feng, M., Zhou, I. W., et al., 2016. Memory impairment, dementia, and Alzheimer's disease in classical and contemporary traditional Chinese medicine. J. Alternat. Complement. Med., 22: 695670.

Milind, P., Deepa, K., 2011. Clove: A champion spice. Int. J. Res. Ayurv. Pharm., 2(1): 47-54.

Misra, S., Medhi, B., 2013. Role of probiotics as memory enhancer. Indian J. Pharmacol., 45: 311312.

Mohan, M., Kaul, N., Punekar, A., Girnar, R., Junnare, P., Patil, L., 2005. Nootropic activity of Moringa oleifera leaves. J. Nat. Remed., 5: 59-62.

Moss, L., Rouse, M., Wesnes, K. A., Moss, M., 2010. Differential effects of the aromas of Salvia species on memory and mood. Hum. Psychopharmacol., 25: 388-396.

Moss, M., Rouse, M., Moss, L., 2014. Aromas of Salvia species enhance everyday prospective memory performance in healthy young adults. Adv. Chem. Eng. Sci., 4: 339-346.

Nahata, A., Patil, U. K., Dixit, V. K., 2010. Effect of Evolvulus alsinoides Linn. on learning behavior and memory enhancement activity in rodents. Phytother. Res., 24: 486-493.

Nahata, A., Patil, U. K., Dixit, V. K., 2008. Effect of Convolvulus pluricaulis Choisy on learning behavior and memory enhancement activity in rodents. Nat. Prod. Res., 22: 1472-1482.

Narasimhan, B., Dhake, S., 2006. Antibacterial principles from Myristica fragrans seeds. J. Med. Food., 9: 395-399.
Nunomura, A., Castellani, R. J., Zhu, X., Moreira, P. I., Perry, G., Smith, M. A., 2006. Involvement of oxidative stress in Alzheimer disease. $\mathrm{J}$. Neuropathol. Exp. Neurol., 65: 631-641.

Obolentseva, G. V., Litvinenko, V. I., Ammosov, A. S., Popova, T. P., Sampiev, A. M., 1999. Pharmacological and therapeutic properties of licorice preparations (a review). Pharm. Chem. J., 33: 24-31.

Obulesu, M., Rao, D., 2011. Effect of plant extracts on Alzheimer's disease: An insight into therapeutic avenues. J. Neurosci. Rural Pract., 2: 56-61.

Ortega, M. G., Vallejo, M. G., Cabrera, J. L., Pérez, M. F., Almirón, R. S., Ramírez, O. A., Agnese, A. M., 2006. Huperzia saururus activity on synaptic transmission in the hippocampus. J. Ethnopharmacol., 104: 374-378.

Pakade, V., Cukrowska, E., Chimuka, L., 2013. Comparison of antioxidant activity of Moringa oleifera and selected vegetables in South Africa. S. Afr. J. Sci., 109: 1-5.

Panday, D. R., Rauniar, G. P., 2016. Effect of rootextracts of Ficus benghalensis (Banyan) in memory, anxiety, muscle co-ordination and seizure in animal models. BMC Complement. Altern. Med., 16: 429.

Parle, M., Dhingra, D., Kulkarni,S., 2004. Improvement of mouse memory by Myristica fragrans seeds. J. Med Food. 7: 157-1661.

Parys, W., 1998. Development of Reminyl® (galanthamine), a novel acetylcholinesterase inhibitor, for the treatment of Alzheimer's disease. Alzheimer's Rep., 53: S19-S20.

Pastorino, G., Cornara, L., Soares, S., Rodrigues, F. M., Oliveira, B. P. P., 2018. Liquorice (Glycyrrhiza glabra): A phytochemical and pharmacological review. Phytother. Res., 32(12): 2323-2339.

Patocka, J., 1998. Huperzine A - an interesting anticholinesterase compound from Chinese herbal medicine. Acta Medica, 41(4): 155-157.

Pingali, U., Pilli, R., Fatima, N., 2014. Effect of standardized aqueous extract of Withania somnifera on tests of cognitive and psychomotor performance in healthy human participants. Pharmacogn. Res., 6: 12-18.

Prasad, S., Aggarwal, B. B., 2011. Turmeric, the golden spice: From traditional medicine to modern medicine. In: Benzie, I. F. F., Wachtel-Galor, S. (Eds.). Herbal Medicine: Biomolecular and Clinical Aspects. $2^{\text {nd }}$ Edn. Boca Raton (FL): CRC Press/Taylor \& Francis.

Pramodinee, D., Mahesh, M., Niranjan, D., Sankpala, 
S., 2011. Memory enhancing activity of Cissampelos papiera in mice. Int. J. Pharm. Sci., 3: 206-211.

Radad, K., Gille, G., Liu, L., Rausch, W. D., 2006. Use of ginseng in medicine with emphasis on neurodegenerative disorders. J. Pharmacol. Sci., 100(3): 175-186.

Rajagopal, P. L., James, A., Premlatha, K., Sajithkumar, P. N., 2013. Herbal options in Alzheimer's diseaseA review. J. Int. Acad. Res. Multidiscipl., 1(9): 178189.

Raja, S., Hoyer, G., 2004. Statins, much more than just a lipid lowering therapy. Indian Heart J., 56: 204209.

Rai, K. S., Murthy, K. D., Karanth, K. S., Nalini, K., Rao, M. S., Srinivasan, K. K., 2002. Clitoria ternatea root extract enhances acetylcholine content in rat hippocampus. Fitoterapia, 73(7-8): 685-689.

Rai, K. S., Murthy, K. D., Karanth, K. S., Rao, M. S., 2001. Clitoria ternatea (Linn.) root extract treatment during growth spurt period enhances learning and memory in rats. Indian J. Physiol. Pharmacol., 45(3): 305-313.

Rainer, M., 1997. Galanthamine in $\mathrm{AD}-\mathrm{a}$ new alternative to tacrine? CNS Drugs, 7: 89-97.

Ramachandran, S., Sanjay, S., Dhanaraju, M., 2013. Antiamnesic effect of Piracetam potentiated with Emblica officinalis and Curcuma longa in aluminium induced neurotoxicity of Alzheimer's disease. Int. J. Adv. Res., 1: 185-196.

Ranpariya, V. L., Parmar, S. K., Sheth, N. R., Chandrashekhar, V. M., 2011. Neuroprotective activity of Matricaria recutita against fluorideinduced stress in rats. Pharmaceut. Biol., 49: 696701.

Rao, R. V., Descamps, O., John, V., et al., 2012. Ayurvedic medicinal plants for Alzheimer's disease: A review. Alz. Res. Therapy, 4: 22.

Reay, J. L., Kennedy, D. O., Scholey, A. B., 2006. Effects of Panax ginseng, consumed with and without glucose, on blood glucose levels and cognitive performance during sustained 'mentally demanding' tasks. J. Psychopharmacol., 20(6): 771781.

Rockwood, K., Mintzer, J., Truyen, L., Wessel, T., Wilkinson, D., 2001. Effects of a flexible galanthamine dose in Alzheimer's disease: A randomized, controlled trial. J. Neurosurg. Psychiat. 71: 589-595.

Roodenrys, S., Booth, D., Bulzomi, S., et al., 2002. Chronic effects of Brahmi (Bacopa monnieri) on human memory. Neuropsychopharmacol., 27: 279281.

Rubio, J., Qiong, W., Liu, X., Jiang, Z., Dang, H., Chen, S., Gonzales, F., 2011. Aqueous extract of black maca (Lepidium meyenii) on memory impairment induced by ovariectomy in mice. Evid. Based Complement. Alternat. Med., 2: 1-5.

Rui, S., Marcelo, S., Sandro, W., 2008. Effects of acute administration of hydroalcoholic extract of mate tea leaves (Ilex paraguariensis) in animal models of learning and memory. J. Ethnopharmacol., 120: 465-473.

Rusu, M. E., Gheldiu, A.-M., Mocan, A., Vlase, L., Popa D-S (2018) Anti-aging potential of tree nuts with a focus on the phytochemical composition, molecular mechanisms and thermal stability of major bioactive compounds. Food Function, 9: 2554-2575.

Russo, P., Frustaci, A., Del Bufalo, A., Fini, M., Cesario, A., 2013. From traditional European medicine to discovery of new drug candidates for the treatment of dementia and Alzheimer's disease: acetyl cholinesterase inhibitors. Curr. Med. Chem., 20: 976-983.

Salehi-Sourmaghi, M. H., Azadi, B., Amin, G. H., Amini, M., Sharifzadeh, M., 2010. The first phytochemical report of Galanthus transcaucasicus Fomin. Daru., 18(2): 124-127.

Sanka, N., Santhipriya, N., Nadendla, R. R., 2018. An updated review on Anti-Alzheimer's herbal drugs. J. Drug Deliv. Therapeut., 8(6): 360-372.

Santos, O. V., Corrêa, N. C. F., Carvalho, R. N., Costa, C. E. F., Lannes, S. C. S., 2013. Yield, nutritional quality, and thermal-oxidative stability of Brazil nut oil (Bertholletia excelsa H.B.K) obtained by supercritical extraction. J. Food Eng., 117: 499504.

Sarwar, S., Rahman, Md. R., Nahar, K., Rahman, M. A., 2014. Analgesic and neuropharmacological actiivties of methanolic leaf extract of Clitoria ternatea Linn. J. Pharm. Phytochem., 2(5): 110 114.

Saxena, V., Ahmad, H., Gupta, R., 2013. Memory enhancing effects of Ficus carica leaves in hexane extract on interoceptive behavioral models. Asian J. Pharm. Clin. Res., 6: 109-113.

Scholey, A. B., Tildesley, N. T., Ballard, C. G., 2008. An extract of Salvia (sage) with anti cholinesterase properties improves memory and attention in healthy older volunteers. Psychopharmacol., 198: 127-139. 
Sehgal, N., Gupta, A., Valli, R. K., Datt Joshi, S., Mills, J.T., Hamel, E., Khanna, P., Jain, S. C., Thakur, S. S., Ravindranath, V., 2012. Withania somnifera reverses Alzheimer's disease pathology by enhancing low-density lipoprotein receptor-related protein in liver. Proc Natl Acad Sci USA. 109:35103515.

Sethiya, N. K., Nahata, A., Mishra, S.H., Dixit, V. K., 2009. An update on Shankhpushpi, a cognitive boosting Ayurvedic medicine. Zhong Xi Yi Jie He Xue Bao, 7: 1001-1022.

Shahriar, M., Alam, F., Uddin, M. M. N., 2014. Analgesic and neuropharmacological activity of Withania somnifera root. Int. J. Pharm., 4: 203-208.

Shakeri, A., Sahebkar, A., Javadi, B., 2016. Melissa officinalis L. - A review of its traditional uses, phytochemistry and pharmacology.J.Ethnopharmacol., 188(21): 204-228.

Sharma, V., Singh, I., Chaudhary, P., 2014. Acorus calamus (The Healing Plant): A review on its medicinal potential, micropropagation and conservation. Nat. Prod. Res., 28: 1454-1466.

Sharma, V., Agrawal, R. C., 2013. Glycyrrhiza glabra: A plant for the future. Mintage J. Pharm. Med. Sci., 2(3): 15-20.

Sharma, V., Sharma, R., Gautam, D. N. S., Kuca, K., Nepovimova, E., Martins, N., 2020. Role of vacha (Acorus calamus Linn.) in neurological and metabolic disorders: Evidence from ethnopharmacology, phytochemistry, pharmacology and clinical study. J. Clin. Med., 9: 1176.

Sharma, K., Bhatnagar, M., Kulkarni, S. K., 2010. Effect of Convolvulus pluricaulis Choisy and Asparagus racemosus Willd on learning and memory in young and old mice: A comparative evaluation. Indian J. Exp. Biol., 48: 479-485.

Shin, Y. J., Park, Y. K., 2014. Effects of different parts of Angelica gigas Nakai on brain damages and neuronal death in transient middle artery occlusion/ reperfusion-induced ischemic rats. Korea J. Herbol., 29: 85-93.

Shukla, P. K., Khanna, V. K., Ali, M. M., Maurya, R., Khan, M. Y., Srimal, R. C., 2006. Neuroprotective effect of Acorus calamus against middle cerebral artery occlusion-induced ischaemia in rat. Hum. Exp. Toxicol., 25: 187-194.

Sowndhararajan, K., Ki, S., 2017. Neuroprotective and cognitive enhancement potentials of Angelica gigas Nakai root: A review. Sci. Pharm., 85: 21.

Sigiura, M., Saito, H., Abe, K., 1995. Ethanol extract of Crocus sativus L. antagonizes the inhibitory action of ethanol on hippocampal long-term potentiation in vivo. Phytother. Res., 9: 100-104.

Singh, R., Sharma, P. K., Malviya, R., 2011. Pharmacological properties and ayurvedic value of Indian buch plant (Acorus calamus): A short review. Adv. Biol. Res., 5: 145-154.

Singhal, A. K., Naithani, V., Bangar, O. P., 2012. Medicinal plants with a potential to treat Alzheimer and associated symptoms. Int. J. Nutr. Pharmacol. Neurol. Dis., 2: 84-91.

Singhal, A. K., 2012. Medicinal plants with a potential to treat Alzheimer and associated symptoms. Int. J. Nutr. Pharmacol. Neurol. Dis., 2(2): 84-91.

Singh, H. K., Dhawan, B. N., 1997. Neuro psycho pharmacological effects of the Ayurvedic nootropic Bacopa monnieri Linn. (Brahmi). Indian J. Pharmacol., 29: 359-365.

Singh, O., Khanam, Z., Misra, N., Srivastava, M. K., 2011. Chamomile (Matricaria chamomilla L.): An overview. Pharmacogn. Rev., 5(9): 82-95.

Srivastava, R., Ahmed, H., Dixit, R. K., Dharamveer, Saraf, S. A., 2010. Crocus sativus L.: A comprehensive review. Pharmacogn. Rev., 4(8): 200-208.

Tabassum, N., Rasool, S., Malik, Z. A., Ahmad, F., 2012. Natural cognitive enhancers. J. Pharm. Res., 5(1): 153-160.

Takeuchi, K. P., Egea, M. B., 2020. Bioactive compounds of the Brazil nut (Bertholletia excelsa Bonpl.): Nutritional and health aspects. In: Murthy H., Bapat, V. (Eds.) Bioactive Compounds in Underutilized Fruits and Nuts. Reference Series in Phytochemistry. Springer, Cham.

Taranahalli, A. D., Cheeramkuzh, T., 2000. Influence of Clitoria ternatea extracts on memory and central cholinergic activity in rats. Pharmaceut. Biol., 38(1): 51-56.

Tian, J., Jing Shi, J., Zhang, X., Wang, Y., 2010. Herbal therapy: A new pathway for the treatment of Alzheimer's disease. Alzheimer's Res. Ther., 2: 30.

Um, M. Y., Ahn, J. Y., Kim, S., Kim, M. K., Ha, T. Y., 2009. Sesaminol glucosides protect beta-amyloid peptide-induced cognitive deficits in mice. Biol. Pharm. Bull., 32(15): 16-20.

Verma, M., 2014. Ethnomedicinal and antimicrobial screening of Bacopa monnieri (L.) Pennell. J. Phytol., 6: 1-6.

Wang, J. P., Hsu, M. F., Raung, S. L., Chen, C. C., Kuo, J. S., Teng, C. M., 1992. Anti-inflammatory and analgesic effects of magnolol. NaunynSchmiedebergs Arch. Pharmacol., 346: 707-712. 
Wang, R., Yan, H., Tang, X., 2006. Progress in studies of huperzine A, a natural cholinesterase inhibitor from Chinese herbal medicine. Acta Pharmacol. Sin., 1, 1-26.

Watkins, P. B., Zimmerman, H. J., Knapp, M. J., Gracon, S. I., Lewis, K. W., 1994. Hepatotoxic effects of tacrine administration in patients with Alzheimer's disease. J. Am. Med. Assoc., 271: 992-
998.

Wernicke, T. F., Reischies, F. M., 1994. Prevalence of dementia in old age: Clinical diagnoses in subjects aged 95 years and older. Neurology, 44: 250-253.

Yang, W. T., Zheng, X. W., Chen, S., et al., 2017. Chinese herbal medicine for Alzheimer's disease: Clinical evidence and possible mechanism of neurogenesis. Biochem. Pharmacol., 141: 143-155.

\section{How to cite this article:}

Malabadi, R. B., Kolkar, K. A., Meti, N. T., Chalannavar, R. K., 2021. Recent updates on the role of herbal medicine for Alzheimer's disease (Dementia). Int. J. Curr. Res. Biosci. Plant Biol. 8(1), 14-45.

doi: https://doi.org/10.20546/ijcrbp.2021.801.002 